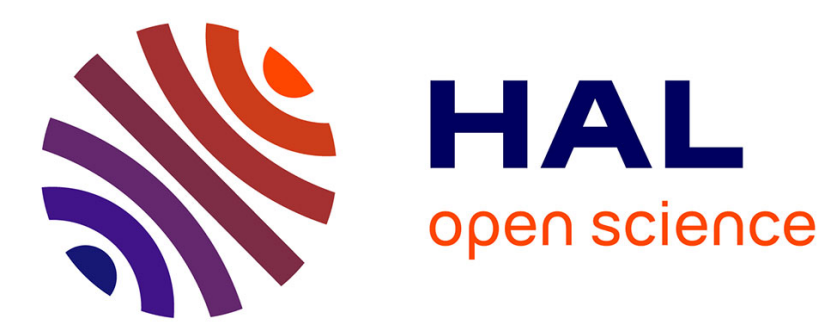

\title{
Unveiling African rainforest composition and vulnerability to global change
}

\author{
M. Réjou-Méchain, Frédéric Mortier, Jean-François Bastin, Guillaume Cornu,
}

Nicolas Barbier, Nicolas Bayol, Fabrice Bénédet, Xavier Bry, Gilles Dauby, Vincent Deblauwe, et al.

\section{To cite this version:}

M. Réjou-Méchain, Frédéric Mortier, Jean-François Bastin, Guillaume Cornu, Nicolas Barbier, et al. Unveiling African rainforest composition and vulnerability to global change. Nature, 2021, 593, pp.90-94. 10.1038/s41586-021-03483-6 . hal-03205277

\section{HAL Id: hal-03205277 \\ https://hal.inrae.fr/hal-03205277}

Submitted on 21 Oct 2021

HAL is a multi-disciplinary open access archive for the deposit and dissemination of scientific research documents, whether they are published or not. The documents may come from teaching and research institutions in France or abroad, or from public or private research centers.
L'archive ouverte pluridisciplinaire HAL, est destinée au dépôt et à la diffusion de documents scientifiques de niveau recherche, publiés ou non, émanant des établissements d'enseignement et de recherche français ou étrangers, des laboratoires publics ou privés. 
1 Title: Unveiling African rainforest composition and vulnerability to global change

2 Authors: Maxime Réjou-Méchain ${ }^{1 *}$, Frédéric Mortier ${ }^{2,3}$, Jean-François Bastin ${ }^{1,2,3,4}$,

3 Guillaume Cornu ${ }^{2,3}$, Nicolas Barbier ${ }^{1}$, Nicolas Bayol ${ }^{5}$, Fabrice Bénédet ${ }^{2,3}$, Xavier Bry ${ }^{6}$,

4 Gilles Dauby ${ }^{1}$, Vincent Deblauwe ${ }^{7,8}$, Jean-Louis Doucet ${ }^{9}$, Charles Doumenge ${ }^{2,3}$, Adeline

5 Fayolle ${ }^{9}$, Claude Garcia ${ }^{2,3,10}$, Jean-Paul Kibambe ${ }^{11,12}$, Jean-Joël Loumeto ${ }^{13}$, Alfred

6 Ngomanda $^{14}$, Pierre Ploton ${ }^{1}$, Bonaventure Sonké ${ }^{15}$, Catherine Trottier ${ }^{6}$, Ruppert Vimal ${ }^{16}$,

7 Olga Yongo ${ }^{17}$, Raphaël Pélissier ${ }^{1}$, Sylvie Gourlet-Fleury ${ }^{2,3}$

\section{Affiliations:}

9 1. AMAP, Univ Montpellier, IRD, CNRS, CIRAD, INRA, Montpellier, France.

10 2. CIRAD, Forêts et Sociétés, F-34398 Montpellier, France.

11 3. Forêts et Sociétés, Univ Montpellier, CIRAD, Montpellier, France.

12 4. Crowther Lab, Department of Environmental Systems Science, Institute of

13 Integrative Biology, ETH Zürich, Zürich, Switzerland.

14 5. Foret Ressources Management Ingénierie, 34130 Mauguio - Grand Montpellier, 15 France.

16 6. Institut Montpelliérain Alexander Grothendieck (IMAG), Montpellier,France.

17 7. Center for Tropical Research, Institute of the Environment and Sustainability,

18 University of California, Los Angeles, LosAngeles, CA 90095, USA.

19 8. International Institute of Tropical Agriculture, Yaounde, Cameroun.

20 9. Université de Liège, Gembloux Agro-Bio Tech, Forest is Life, TERRA Teaching and 21 Research Centre, Passage des Déportés 2, 5030 Gembloux, Belgium.

22 10. Forest Management and Development Team, Department of Environmental 23 System Science, Institute of Integrative Biology, ETH Zürich, Zürich, Switzerland.

24 11. Faculté des Sciences Agronomiques, Département de Gestion des Ressources

25 Naturelles, Université de Kinshasa, Kinshasa I, Democratic Republic of Congo.

26 12. Wildlife Conservation Society, Kinshasa, Congo, Democratic Republic of Congo. 
27 13. Faculté des Sciences et Techniques, Université Marien Ngouabi, BP 69

28 Brazzaville, Republic of Congo.

29 14. Institut de Recherche en Ecologie Tropicale (IRET/CENAREST), B.P. 13354

30 Libreville, Gabon.

31 15. Plant Systematic and Ecology Laboratory, Higher Teacher's Training College,

32 University of Yaoundé I, Yaoundé, Cameroon.

33 16. GEODE UMR 5602, CNRS, Université Jean-Jaurès, 5 Allée Antonio-Machado,

34 Toulouse, France.

35 17. Laboratoire de Biodiversité Végétale et Fongique, Faculté des Sciences, Université 36 de Bangui, Bangui, Central African Republic. 
38 Africa is forecasted to experience large and rapid climate change ${ }^{1}$ and population

39 growth ${ }^{2}$ during the XXIst century, threatening the world's second largest

40 rainforest. Protecting and sustainably managing these forests requires an

41 extended understanding of their current compositional heterogeneity,

42 environmental drivers and vulnerability to ongoing changes. Here, using an

43 unprecedented dataset of 6 million trees in more than 180,000 field plots, we

44 jointly model the distribution in abundance of the most dominant central African

45 tree taxa and produce the first continuous maps of the floristic and functional

46 composition of central African forests. Our results show that the uncertainty in

47 taxon-specific distributions averages out at the community level, revealing highly

48 deterministic assemblages. We uncover contrasting floristic and functional

49 compositions across climate, soil types and anthropogenic gradients, with

50 functional convergence among floristically dissimilar forest types. Combining

51 these spatial predictions with global change scenarios suggests a high

52 vulnerability of the northern and southern forest margins, the Atlantic forests and

53 of most forests from the Democratic Republic of Congo where both climate and

54 anthropogenic threats are expected to increase sharply by 2085 . These results

55 constitute key quantitative benchmarks for scientists and policy makers to shape

56 transnational conservation and management strategies aiming at providing a

57 sustainable future for central African forests.

58 Concomitant increases in climate stress, human population needs and resource

59 extraction in central Africa raise environmental concerns ${ }^{3-5}$. These threats may have

60 considerable impacts on the carbon budget ${ }^{6}$, climate $^{7}$ and biodiversity of central African

61 forests $^{8}$, which shelter some of the world's most iconic wildlife species and that are

62 already experiencing much drier and seasonal climate than other tropical forests ${ }^{9}$.

63 However, the current composition of central African forests and its determinants at

64 regional scale are still poorly known, being often studied on limited areas ${ }^{10-12}$ and

65 datasets ${ }^{13}$ or at a very coarse grain with heterogeneous presence-only data ${ }^{14}$. Vast

66 areas remain poorly scientifically explored ${ }^{15}$ while most spaceborne systems of Earth 
67 observation provide very limited information on forest composition ${ }^{16}$. This limits our 68 ability to understand how forest composition and functions vary regionally, to forecast 69 how these forests will face upcoming global changes and, ultimately, to anticipate, on 70 scientific bases, how to protect and manage them beyond national boundaries.

71 In this study, we used an unprecedented forest inventory dataset to (1) model the main

72 floristic and functional gradients over central African forests, and (2) assess their 73 expected vulnerability under forecasted global (climatic and anthropogenic) change 74 conditions. We compiled the abundance distributions of 193 dominant tree taxa in 75185,665 field plots (ca. 90,000 ha) from commercial forest inventories spread over the 76 five main forested countries in central Africa (Extended Data Fig. 1). We modeled the 77 joint distributions of taxon abundances at a $10-\mathrm{km}$ resolution using supervised 78 component generalized linear regression (SCGLR) ${ }^{17}$, a modelling method that extends 79 partial least squares (PLS) regression to the multivariate generalized linear framework.

80 SCGLR models a set of responses (here the abundances of taxa) from synthetic

81 orthogonal explanatory components derived from 24 climatic variables (hereafter, 82 climatic components, CCs) and additional soil type (here, sand vs. clay) and 83 anthropogenic pressure covariates. We developed for this study an index based on 84 population density and road network specifically designed and calibrated to predict 85 recent human-induced forest disturbance intensity in central Africa - see Methods.

86 Finally, thanks to the huge size of the dataset, the predicted floristic and functional 87 gradients were cross-validated with spatially independent observations using Spearman 88 correlation coefficients, $\rho_{C V}$.

\section{Floristic composition in central Africa}

90 Our model predicted individual taxon abundances with an overall median correlation $\rho_{C V}$ 91 of 0.48 (range of -0.11 to 0.83 ). This median was still as high as 0.45 when unoccupied 92 sites were removed, showing that, beyond presence-absence, our model also captured 93 variations in abundances within taxon's distributional range. A correspondence analysis

94 (CA) performed on the predicted taxon abundances revealed major regional floristic 95 gradients (Fig. 1; Extended Data Fig. 2 and 3) highly correlated with the observed 
96 gradients ( $\rho_{C V}=0.89,0.71$ and 0.6 for $\mathrm{CA}$ axes 1 to 3 , respectively; Fig. 1B-D). Contrary

97 to Amazonian and Southeast Asian forests, where soil was shown to be the primary

98 large scale driver of tree community composition ${ }^{18,19}$, the most prominent floristic

99 gradient predicted here (CA axis 1 ) was highly related to climate, in particular to the first

100 predictive CC (Pearson's $r=0.98$ ), contrasting areas with a cool and light-deficient ${ }^{20}$ dry

101 season (coastal Gabon) and areas with high evapotranspiration rates (northern limit of

102 the central African forests; Extended Data Fig. 4). The second predicted floristic

103 gradient (CA axis 2 ) was highly correlated with the two other CCs ( $r=-0.86$ and -0.72 for

104 CC2 and CC3, respectively) related to seasonality and maximum temperature, thus

105 contrasting equatorial areas with a low water deficit and areas with a high water deficit

106 towards the limits of the tropics. Climate seasonality was also found to be an important

107 driver of tree community composition in Amazonia ${ }^{18}$ and maximum temperature has

108 been recently identified as the most important pantropical driver of forest biomass,

109 impacting woody productivity ${ }^{21}$. The third predicted floristic gradient (CA axis 3 ) revealed

110 more local floristic variations highlighting human-impacted forests $(r=0.67$ with our index

111 of human-induced forest disturbance intensity).

112 As already shown in previous studies ${ }^{22,23}$, the association between taxon distributions

113 and climate patterns may appear by chance because both are spatially autocorrelated

114 at the regional scale. We thus used a spatially explicit null model that randomized the

115 predictive CCs while preserving their spatial (co)structures. When keeping the soil and

116 human impact on forests unchanged, the null model did not predict significantly different

117 abundances ( $P>0.1)$ from those predicted with original $C C$ s for $67 \%$ of the taxa. This

118 suggests that variation in taxon abundances directly depends on climate for a minimum

119 of only one-third of the taxa, while for most of them, abundance may correlate with

120 climate by chance only. In contrast, the association between climate and the main

121 gradients of floristic assemblages was robust to autocorrelation artifacts $(P=0.028$,

1220.006 and 0.06 for $\mathrm{CA} 1$ to 3 , respectively). This result confirms that extrapolating

123 assemblages from climate variables is more reliable than extrapolating individual taxon

124 abundances ${ }^{24}$. Indeed, individual taxon abundances are likely less predictable on the 
125 basis of only current drivers since they are also affected by unknown past human

126 disturbances ${ }^{25}$, biotic interactions and biogeographical history ${ }^{26}$, the idiosyncratic effects

127 of which tend to average out at the community level.

\section{Functional composition in central Africa}

129 From the predicted floristic assemblages, we computed the community weighted mean ${ }^{27}$

130 of three functional traits known to play an important role in ecosystem processes: wood

131 density, deciduousness and maximum diameter (Fig. 2). The predicted functional

132 composition was consistent with the observations $\left(\rho_{C V}=0.47,0.75\right.$ and 0.45 for the three

133 traits, respectively; Extended Data Fig. 5). As in Amazonia ${ }^{18}$, community wood density

134 varies with soil type with the highest values found on sandy soils, at the boundaries of

135 Cameroon, Republic of Congo and Central African Republic, where tree species with

136 conservative resource use strategies predominate ${ }^{11}$. However, larger scale variations in

137 wood density were primarily driven by human-induced forest disturbances, with a lower

138 community wood density in human-impacted forests, indicating that they are mostly

139 composed of fast-growing taxa ${ }^{28}$. However, these areas also feature a high proportion of

140 trees that can potentially reach a large diameter. These two results indicate that human-

141 impacted forests are dominated by long-lived pioneer taxa, which are characterized by a

142 low wood density but a large potential stature, offering a fast and relatively long-lasting

143 carbon sink potential in absence of disturbances ${ }^{29}$. Finally, a marked deciduousness

144 gradient ran from the highly evergreen forests of coastal Gabon to the northern limit of

145 the central African forests with, again, a well-known exception on the northern sandy

146 soil plateau ${ }^{11,30}$.

\section{A reference map of forest types}

148 To ease practical applications, we performed hierarchical clustering of the predicted

149 floristic gradients (pixel scores on the first five CA axes), which are continuous by

150 nature, and identified ten major forest types (Fig. 3; Extended Data Table 1). The

151 strongest floristic dissimilarity appeared between Atlantic forests (types 1 to 3 ) and the

152 other forest types (4 to 10), within which semideciduous seasonal forests were clearly 
153 distinguished (types 4 to 6 ). We also observed functional convergences among

154 floristically dissimilar forest types and vice versa. For example, despite having a

155 regional species pool similar to deciduous forests (types 4 and 6), sandstone forests

156 (type 5) have a functional composition closer to remote forest groups (e.g. types 2, 3, 7

157 and 8), with high wood density and low deciduousness. Soil filtering indeed modifies the

158 relative abundance of species (rather than their presence or absence ${ }^{31}$ ) favoring

159 suitable functional attributes in poor sandy soils ${ }^{11}$. By contrast, while Atlantic forests

160 (types 1 to 3 ) have little taxonomic affinity with the east-central and southern forests

161 (types 7 and 8), they display similar functional composition due to more similar climate

162 conditions, as represented on the first predictive CC (Extended Data Table 1). This

163 confirms that while taxonomic composition has an important biogeographical

164 component, the functional composition of tree communities can converge in similar

165 environmental conditions.

\section{Vulnerability to global change}

167 For the ten forest types, most climate models predict current climate conditions either to

168 virtually disappear from central Africa (e.g., types 2 and 5; Extended Data Fig. 6), or to

169 move at spatial and temporal scales incommensurate with tree dispersal ability

170 (e.g. types 4 and 6). This suggests that current forest communities will not be able to

171 track their present climate envelopes and will face the emergence of novel climates,

172 making the prediction of taxon distributions under future climate projection highly risky ${ }^{32}$.

173 We thus assessed the vulnerability of central African forests to climate change through

174 their sensitivity, exposure, and adaptive capacity, following the recommendation of the

$175 \mathrm{IPCC}^{33}$.

176 We quantified sensitivity at the community level using the inverse of the current climate 177 niche breadth of taxa (Fig. 4C) and assuming that assemblages dominated by taxa with

178 narrow environmental tolerances will be more vulnerable to upcoming changes ${ }^{34}$.

179 Sensitivity appeared to be high in coastal Gabon (type 2), where a high level of species

180 endemism exists ${ }^{35}$ and in the driest northern margin of central African forests. Recent

181 studies consistently showed that drier tropical forests exhibited larger functional 
182 changes than wetter forests in response to a long-term drought in west Africa ${ }^{36}$ and are 183 likely to be more sensitive to global warming ${ }^{21}$. By contrast, forests from the northwest 184 Cameroon displayed a relatively low sensitivity to current climate conditions, probably 185 because these forests are dominated by widespread tree taxa adapted to anthropogenic 186 pressure (Fig. 2). Long-lived pioneers, typical of these human-impacted forests, are also 187 expected to be favored by a possible acceleration in forest dynamics induced by global 188 change $^{37,38}$.

189 Exposure to climate change was quantified as the extent to which the current climate 190 determinants ( $C C 1$ to 3 ) are expected to change by 2085 , using 18 unique bias-

191 corrected climate model combinations (under the IPCC-AR5 RCP 4.5 scenario; see

192 Extended Data Fig. 7 for other scenarios). We found that exposure to climate change 193 was mostly driven by an increase in drought stress and maximum temperature (Fig. S2, 194 see also $\left.{ }^{4,39}\right)$. The central and east part of central African forests are predicted to be the 195 most exposed, particularly in the south of the Democratic Republic of Congo (DRC) 196 (Fig. 4D). Note, however, that climate change predictions in central Africa are uncertain 197 because meteorological data for model validation are lacking ${ }^{4}$ (Fig. S3).

198 Finally, we assessed the adaptive capacity of tree communities through their 199 evolutionary potential. We first found highly significant niche conservatism along the first 200 two climate components $(P<0.002)$. This indicates that closely related taxa tend to share 201 similar climate niche spaces at the regional scale and suggests that they could be 202 impacted similarly by future climate change. We thus assumed that higher local 203 phylogenetic diversity provides a wider range of potential responses to novel climate 204 conditions $^{40}$, similarly to the insurance hypothesis ${ }^{41}$. We thus used the phylogenetical 205 diversity of predicted tree assemblages as a proxy of their adaptive capacity to climate 206 change. Undisturbed semideciduous and transitional forests (types 6 and 10 in Fig. 3) 207 appeared phylogenetically more diverse, thus having higher adaptive capacity, than 208 evergreen forests (Fig. 4E). A recent study in Amazonia ${ }^{42}$ also found a peak of 209 phylogenetic diversity at intermediate precipitation level, where dry- and wet-adapted 210 lineages are mixing. As expected ${ }^{43}$, we also found that human-impacted areas tended to 
211 have a low phylogenetic diversity and hence a lower adaptive capacity to climate

212 change.

213 The resulting vulnerability of tree communities to climate change did not correlate with

214 the expected human impact on forests in 2085 ( $\rho=-0.08$ ), here assessed using country-

215 specific projections of human population (Fig. 4A; Extended Data Fig. 8). Vulnerability to

216 climate change is expected to be higher for communities dominated by hard-wooded

217 taxa ( $\rho=0.46$ with wood density, Table S1). By contrast, forecasted human impact on

218 forests is predicted to be higher in already disturbed communities, i.e., dominated by

219 light-wooded taxa with a large potential size ( $\rho=-0.4$ and 0.43 , respectively). However,

220 because we did not account for the appearance of new roads by 2085 , we may

221 underestimate the effect of future anthropogenic activities in remote, currently

222 undisturbed forests. Vulnerability to both climate change and anthropogenic activities

223 (pink color in Fig. 4A) is predicted to be high for forests from coastal Gabon, in large

224 areas from DRC and in the northern margin of the forest domain. Forests from

225 Cameroon and in the south of the Republic of Congo mostly appear vulnerable due to

226 the high expected human impact on forests by 2085 (orange patches in Fig. 4A). By

227 contrast, the tri-national Sangha transboundary forest complex and the northeastern

228 part of Gabon appeared as the least vulnerable area in the region (the large green

229 patch in Fig. 4A). Globally, DRC, which comprises most of the central African forests,

230 mainly contains forests that are predicted to be vulnerable to climate change and/or to

231 anthropogenic pressure (blues to pink patches in Fig. 4A).

\section{Conclusions and perspectives}

233 While some country-specific vegetation patterns were already suggested by

234 phytogeographers, here we provide the first synoptic view of central African forest

235 composition at a fine resolution, based on an unprecedented amount of quantitative

236 data. Unveiling the functional composition of central African forests conveys important

237 insights on their functioning, dynamics and carbon uptake potential and on the way they

238 could respond to global change. Accounting for forest functional characteristics can also

239 considerably reduce uncertainty in large-scale vegetation models ${ }^{44}$ or improve remote 
240 sensing approaches, for example, by assimilating large-scale variation in wood density 241 into forest carbon maps ${ }^{45}$. Our maps may also help scientists to design representative 242 sampling to better understand the long-term impact of climate change on tree species 243 and stand dynamics, e.g., monitoring under-represented forest types or areas highly 244 vulnerable to climate change.

245 The forest types and vulnerability maps should guide the development of new land use 246 plans that preserve the full range of evolutionary and functional potential of today's 247 forests or, at least, that maintain their connectivity to attenuate the threats related to 248 expected changes. In central Africa, protected areas and logging concessions, which 249 cover almost half of the forest domain (14.9\% and 32.2\%, respectively; Extended Data 250 Fig. 9), are important to consider in such plans. Protected areas do not equally cover 251 the ten identified forest types (4 to 54\%; Extended Data Table 1) and should therefore 252 be extended to reach a better representativity. How estimated vulnerability should be 253 accounted for when designing protected areas, e.g., by extending the network in 254 vulnerable areas to minimize biodiversity loss, or in areas with low anthropogenic 255 pressure to improve their protection, is subject to debate ${ }^{46}$. Logging concessions can

256 also contribute to the maintenance of forest cover and functions, providing that they are 257 well managed ${ }^{47,48}$, and currently likely act like biodiversity corridors between protected 258 areas $^{49}$. However, this will only prove effective in the long term if they strictly comply 259 with legislation and, ideally, with standard certification requirements. These good 260 practices are especially important in forests dominated by evergreen taxa with high 261 wood density, where disturbances may have a higher impact on community 262 composition. In areas expected to be under high anthropogenic pressure, forest 263 connectivity could be preserved by promoting agroforestry and restoration programs, 264 strictly controlling access to logging roads and stabilizing shifting agriculture ${ }^{50}$. Over 265 central Africa, the highest uncertainties for the future of forests remain in DRC, where 266 substantial areas, belonging to the state, are not yet attributed to any land use category 267 and should deserve particular attention due to their high vulnerability (Fig. 4). 


\section{Main references}

270 1. Diffenbaugh, N. S. \& Giorgi, F. Climate change hotspots in the CMIP5 global climate 271 model ensemble. Climatic change 114, 813-822 (2012).

272 2. United Nations, Department of Economic and \& Social Affairs, Population Division.

273 World Population Prospects: The 2017 Revision, Key Findings and Advance Tables.

274 Working Paper ESA/P/WP/248, (2017).

275 3. Malhi, Y., Adu-Bredu, S., Asare, R. A., Lewis, S. L. \& Mayaux, P. African rainforests:

276 Past, present and future. Philosophical Transactions of the Royal Society B: Biological 277 Sciences 368, 20120312 (2013).

278 4. James, R., Washington, R. \& Rowell, D. P. Implications of global warming for the 279 climate of African rainforests. Philosophical Transactions of the Royal Society B:

280 Biological Sciences 368, 20120298 (2013).

281 5. Abernethy, K., Maisels, F. \& White, L. J. Environmental issues in central Africa.

282 Annual Review of Environment and Resources 41, 1-33 (2016).

283 6. Hubau, W. et al. Asynchronous carbon sink saturation in African and Amazonian 284 tropical forests. Nature 579, 80-87 (2020).

285 7. De Wasseige, C., Tadoum, M., Atyi, E. \& Doumenge, C. The forests of the Congo 286 Basin-Forests and climate change. (Weyrich, 2015).

287 8. Stévart, T. et al. A third of the tropical African flora is potentially threatened with 288 extinction. Science advances 5, eaax9444 (2019).

289 9. Parmentier, I. et al. The odd man out? Might climate explain the lower tree alpha290 diversity of African rain forests relative to Amazonian rain forests? Journal of Ecology 291 95, 1058-1071 (2007). 
292 10. Réjou-Méchain, M. et al. Regional variation in tropical forest tree species

293 composition in the Central African Republic: An assessment based on inventories by

294 forest companies. Journal of Tropical Ecology 24, 663-674 (2008).

295 11. Réjou-Méchain, M. et al. Tropical tree assembly depends on the interactions 296 between successional and soil filtering processes. Global Ecology and Biogeography 297 23, 1440-1449 (2014).

298 12. Fayolle, A. et al. Geological substrates shape tree species and trait distributions in 299 african moist forests. PLoS ONE 7, e42381 (2012).

300 13. Fayolle, A. et al. Patterns of tree species composition across tropical African forests.

301 Journal of Biogeography 41, 2320-2331 (2014).

302 14. Droissart, V. et al. Beyond trees: Biogeographical regionalization of tropical Africa. 303 Journal of biogeography 45, 1153-1167 (2018).

304 15. Sosef, M. S. et al. Exploring the floristic diversity of tropical Africa. BMC biology 15, 30515 (2017).

306 16. Parmentier, I. et al. Predicting alpha diversity of African rain forests: Models based 307 on climate and satellite-derived data do not perform better than a purely spatial model. 308 Journal of Biogeography 38, 1164-1176 (2011).

309 17. Bry, X., Trottier, C., Verron, T. \& Mortier, F. Supervised component generalized 310 linear regression using a pls-extension of the fisher scoring algorithm. Journal of

311 Multivariate Analysis 119, 47-60 (2013).

312 18. Steege, H. ter et al. Continental-scale patterns of canopy tree composition and 313 function across Amazonia. Nature 443, 444-447 (2006).

314 19. Slik, J. F. et al. Soils on exposed Sunda Shelf shaped biogeographic patterns in the 315 equatorial forests of Southeast Asia. Proceedings of the National Academy of Sciences 316 108, 12343-12347 (2011). 
317 20. Philippon, N. et al. The light-deficient climates of western Central African evergreen

318 forests. Environmental Research Letters 14, 034007 (2019).

319 21. Sullivan, M. J. P. et al. Long-term thermal sensitivity of Earth's tropical forests.

320 Science $\mathbf{3 6 8}, 869-874$ (2020).

321 22. Beale, C. M., Lennon, J. J. \& Gimona, A. Opening the climate envelope reveals no 322 macroscale associations with climate in European birds. Proceedings of the National 323 Academy of Sciences 105, 14908-14912 (2008).

324 23. Deblauwe, V. et al. Remotely sensed temperature and precipitation data improve 325 species distribution modelling in the tropics. Global Ecology and Biogeography 25, 443326454 (2016).

327 24. Maguire, K. C. et al. Controlled comparison of species-and community-level models 328 across novel climates and communities. Proc. R. Soc. B 283, 20152817 (2016).

329 25. Morin-Rivat, J. et al. Present-day central African forest is a legacy of the 19th 330 century human history. Elife 6, (2017).

331 26. Ricklefs, R. E. Intrinsic dynamics of the regional community. Ecology Letters 18, 332 497-503 (2015).

333 27. Violle, C. et al. Let the concept of trait be functional! Oikos 116, 882-892 (2007).

334 28. Díaz, S. et al. The global spectrum of plant form and function. Nature 529, 167-171 335 (2016).

336 29. Rüger, N. et al. Demographic trade-offs predict tropical forest dynamics. Science $337368,165-168(2020)$.

338 30. Ouédraogo, D.-Y. et al. The determinants of tropical forest deciduousness:

339 Disentangling the effects of rainfall and geology in central Africa. Journal of Ecology 340 104, 924-935 (2016). 
341 31. Shipley, B. From plant traits to vegetation structure: Chance and selection in the 342 assembly of ecological communities. (Cambridge University Press, 2010).

343 32. Feeley, K. J. \& Silman, M. R. Biotic attrition from tropical forests correcting for 344 truncated temperature niches. Global Change Biology 16, 1830-1836 (2010).

345 33. Parry, M. et al. Climate change 2007-impacts, adaptation and vulnerability: Working 346 group II contribution to the fourth assessment report of the IPCC. 4, (Cambridge 347 University Press, 2007).

348 34. Foden, W. B. et al. Identifying the world's most climate change vulnerable species: 349 A systematic trait-based assessment of all birds, amphibians and corals. PloS one 8, 350 (2013).

351 35. Lachenaud, O., Stévart, T., Ikabanga, D., Ndjabounda, E. C. N. \& Walters, G. The 352 littoral forests of the Libreville area (Gabon) and their importance for conservation:

353 Description of a new endemic species (Rubiaceae). (2013).

354 doi:info:doi/10.5091/plecevo.2013.744

355 36. Aguirre-Gutiérrez, J. et al. Drier tropical forests are susceptible to functional 356 changes in response to a long-term drought. Ecology Letters 22, 855-865 (2019).

357 37. Claeys, F. et al. Climate change would lead to a sharp acceleration of Central 358 African forests dynamics by the end of the century. Environmental Research Letters 14, $359044002(2019)$.

360 38. McDowell, N. G. et al. Pervasive shifts in forest dynamics in a changing world. 361 Science 368, (2020).

362 39. Zhou, L. et al. Widespread decline of Congo rainforest greenness in the past 363 decade. Nature 509, 86 (2014).

364 40. Purvis, A. Phylogenetic Approaches to the Study of Extinction. Annual Review of 365 Ecology, Evolution, and Systematics 39, 301-319 (2008). 
366 41. Yachi, S. \& Loreau, M. Biodiversity and ecosystem productivity in a fluctuating 367 environment: The insurance hypothesis. Proceedings of the National Academy of 368 Sciences 96, 1463-1468 (1999).

369 42. Neves, D. M. et al. Evolutionary diversity in tropical tree communities peaks at 370 intermediate precipitation. Scientific reports 10, 1-7 (2020).

371 43. Letcher, S. G. Phylogenetic structure of angiosperm communities during tropical

372 forest succession. Proceedings of the Royal Society B: Biological Sciences 277, 97-104 373 (2010).

374 44. Fyllas, N. M., Quesada, C. A. \& Lloyd, J. Deriving Plant Functional Types for 375 Amazonian forests for use in vegetation dynamics models. Perspectives in Plant 376 Ecology, Evolution and Systematics 14, 97-110 (2012).

377 45. Mitchard, E. T. A. et al. Markedly divergent estimates of Amazon forest carbon 378 density from ground plots and satellites. Global Ecology and Biogeography 23, 935-946 379 (2014).

380 46. Visconti, P., Pressey, R. L., Bode, M. \& Segan, D. B. Habitat vulnerability in 381 conservation planning —when it matters and how much. Conservation Letters 3, 404$382414(2010)$.

383 47. Putz, F. E. et al. Sustaining conservation values in selectively logged tropical 384 forests: The attained and the attainable. Conservation Letters 5, 296-303 (2012).

385 48. Gourlet-Fleury, S. et al. Tropical forest recovery from logging: A 24 year silvicultural 386 experiment from Central Africa. Phil. Trans. R. Soc. B 368, 20120302 (2013).

387 49. Clark, C. J., Poulsen, J. R., Malonga, R. \& Jr, P. W. E. Logging Concessions Can 388 Extend the Conservation Estate for Central African Tropical Forests. Conservation 389 Biology 23, 1281-1293 (2009).

390 50. Curtis, P. G., Slay, C. M., Harris, N. L., Tyukavina, A. \& Hansen, M. C. Classifying 391 drivers of global forest loss. Science 361, 1108-1111 (2018). 
393 Figures

394
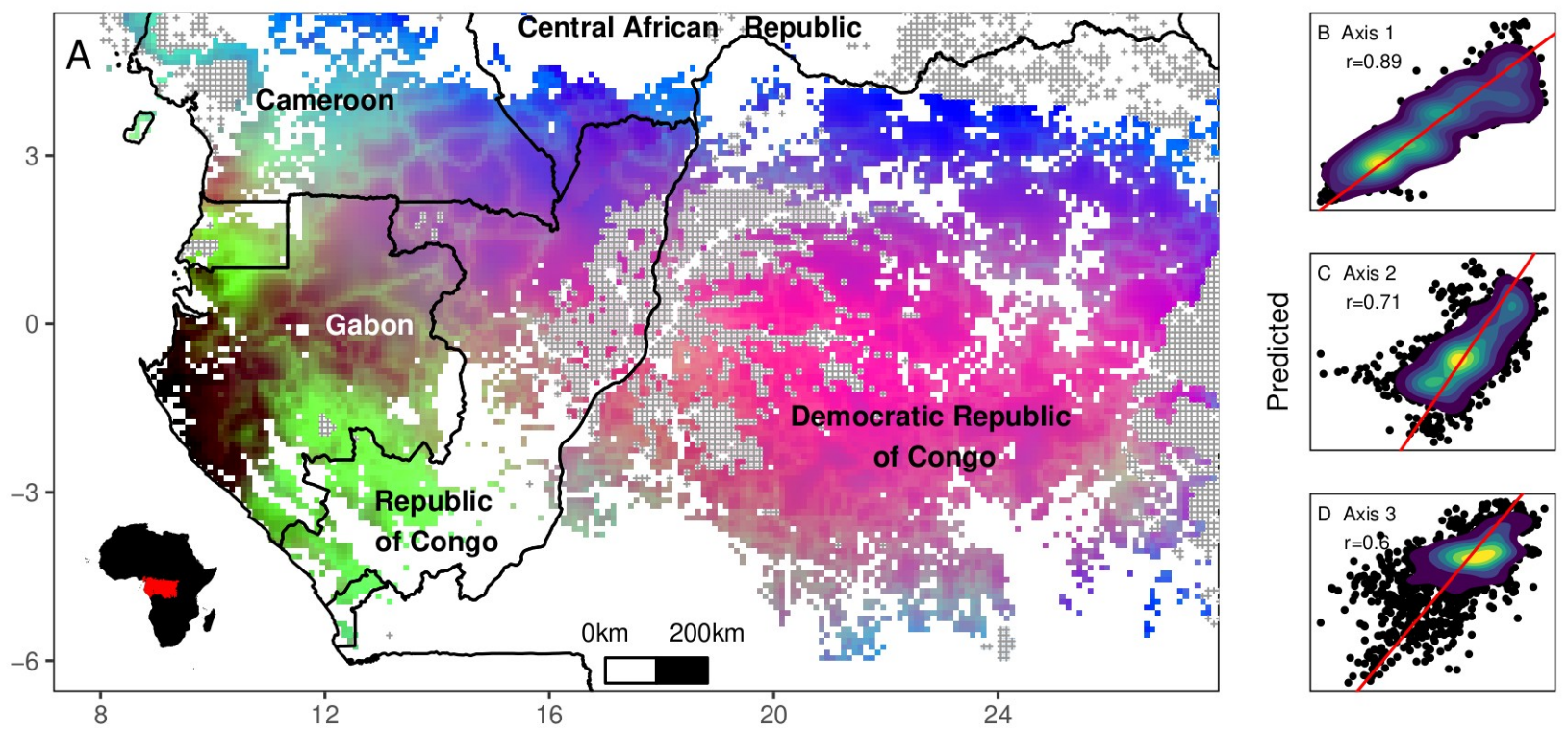

Observed

395 Figure 1: Floristic composition of central African forests. A, Spatialized RGB

396 composition of the three first axes of a correspondence analysis (CA) performed on

397 jointly predicted taxon abundances at $10-\mathrm{km}$ resolution ( $\mathrm{n}=193$ taxa; axis 1 : blue, axis 2:

398 red, axis 3: green). Grey crosses represent forested areas outside the calibration

399 domain, including permanently flooded forests and country boundaries are represented

400 in black. Right panels B-D provide cross-validation results comparing the observed and

401 predicted CA gradients (1:1 line in red). Taxon CA planes 1-2 and 1-3 are given in

402 Extended Data Fig. 2.

403

404 

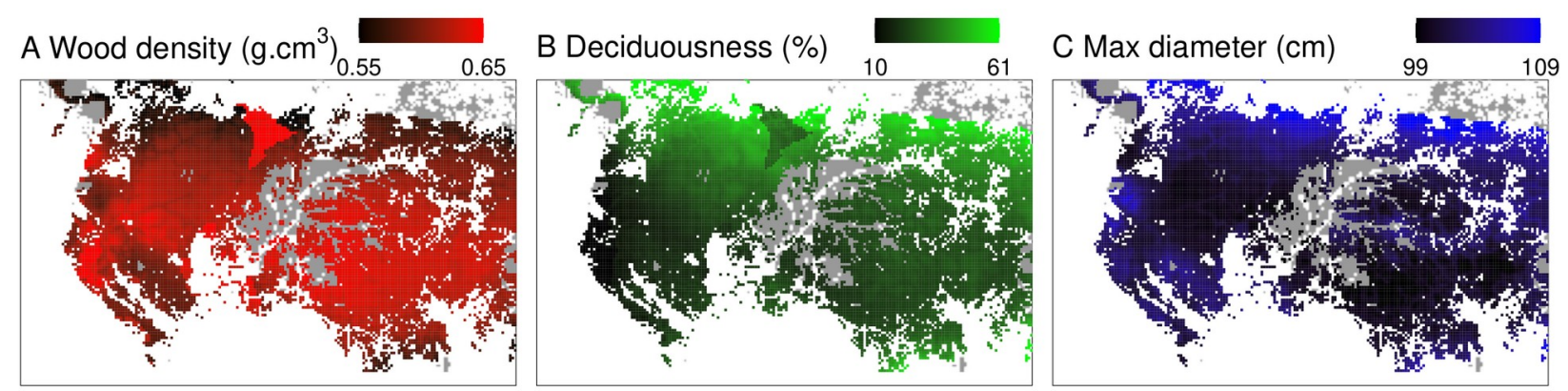

406 Figure 2: Predicted functional composition of central African forests. A-C,

407 Predicted community weighted functional trait values at $10-\mathrm{km}$ resolution. 


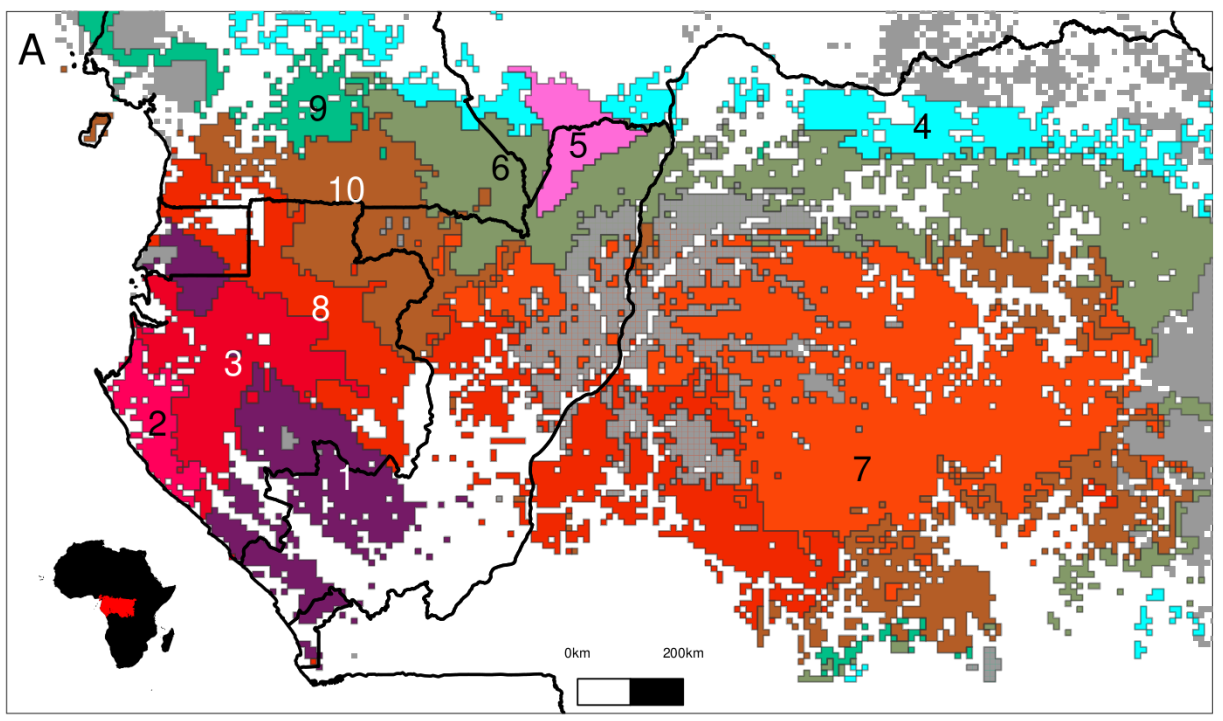

B $\square$ Out of calibration

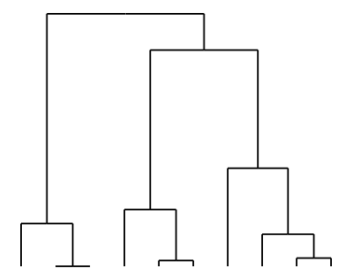

12345678910

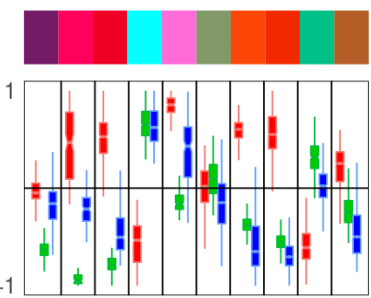

409 Figure 3: Main forest types across central Africa and their functional composition.

410 A, Forest type classification obtained by hierarchical clustering of the predicted floristic

411 gradients. Colors represent a RGB composite of the mean values of the three functional

412 traits per forest type (see Fig. 2), viz. wood density (red), deciduousness (green) and

413 maximum diameter (blue). Thus similar colors illustrate similar functional composition.

414 B, Taxonomic relationships among the forest types illustrated by a clustering

415 dendrogram (top) and a boxplot of the standardized predicted functional composition

416 over the 12,295 grid cells (bottom), with wood density in red, deciduousness in green

417 and maximum diameter in blue (median is reported at the center, the lower and upper

418 hinges correspond to the first and third quartiles and the two whiskers extend from

419 these two quartiles to the largest and smallest values, at most 1.5 times the inter-

420 quartile range from the hinge). Forest type names and additional information are

421 provided in Extended Data Table 1. Clustering uncertainty is reported in Fig. S1. 
A Vulnerability to global change
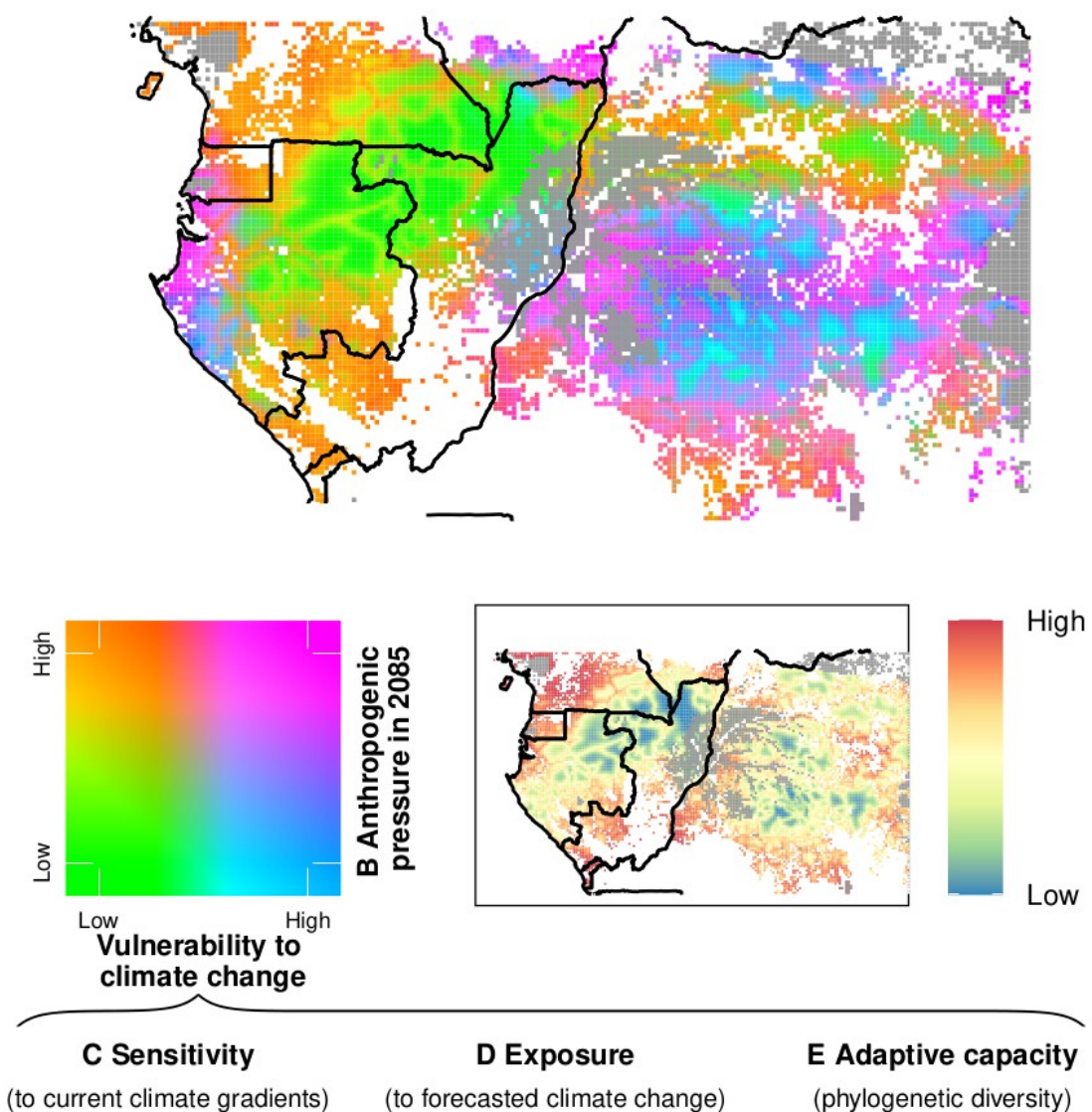

E Adaptive capacity

(to current climate gradients)

(to forecasted climate change)

(phylogenetic diversity)

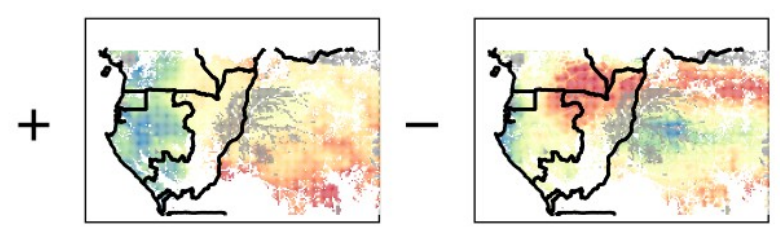

423 Figure 4: Predicted vulnerability of central African tree communities to global

424 changes. A, Composite map of the vulnerability to climate change and of the

425 forecasted human-induced forest disturbance intensity by 2085 . B, Projected human-

426 induced forest disturbance intensity in 2085. Vulnerability to climate change was

427 estimated as the sensitivity to current climate (C) plus the exposure to forecasted

428 climate changes by 2085 (under RCP scenario 4.5) (D) minus the adaptive capacity of

429 tree communities using phylogenetic diversity as a proxy (E). 


\section{METHODS}

\section{Floristic and functional trait data}

433 Forestry data were extracted from management forest inventories conducted in 105

434 logging concessions covering ca. $1.6 \times 10^{5} \mathrm{~km}^{2}$ (Extended Data Fig. 1). Most companies

435 followed a standardized inventory protocol similar to that described in Réjou-Méchain et

436 al. ${ }^{51}$. In most cases, it consisted of continuous and parallel transects $20 \mathrm{~m}$ or $25 \mathrm{~m}$ wide,

437 often $2-3 \mathrm{~km}$ apart, and subdivided into rectangular 0.4 or 0.5 -ha plots. Overall, the full

438 dataset had a total of 192,972 plots. Within each plot, trees with a diameter at breast

439 height $(\mathrm{DBH}) \geq 30 \mathrm{~cm}$ were allocated into $10-\mathrm{cm}$ wide diameter classes and identified at

440 the species or genus level whenever possible through either commercial or local

441 names ${ }^{51}$. Independent analyses performed on 298 scientific plots ( $\geq 1$ ha in size)

442 showed that the floristic gradients obtained with large trees are representative of the

443 ones obtained with trees $\geq 10 \mathrm{~cm}$ in diameter (Pearson $r>0.94$; Fig. S4). Overall, ca.

$4447 \times 10^{6}$ trees were recorded. Taxonomy was revised and homogenized using the African

445 Flowering Plants Database (http://www.ville-ge.ch/musinfo/bd/cjb/africa/index.php?

446 langue=an, last access on 01/09/2019) and the Angiosperm Phylogeny Group III for

447 orders and families ${ }^{52}$. A total of 1,092 taxa were recorded in the original dataset.

448 Extensive botanical controls demonstrated that the patterns of both intra (alpha)- and

449 inter (beta)- plot diversity extracted from these data were highly reliable ${ }^{51}$.

450 For the purpose of the present paper, we conducted an additional assessment

451 according to botanical experts and by comparing the distributional range of our taxa with

452 that in other datasets ${ }^{53,54}$ to select a set of species and genera deemed to be reliably

453 identified over the whole study area $(n=195)$. The abundances of these taxa were

454 aggregated in $10 \times 10-\mathrm{km}^{2}$ grid cells across the study area, but we only kept the taxa

455 occurring in at least $5 \%$ of the cells to discard taxa that cannot be studied at the regional

456 scale $(n=2)$. For the statistical analyses, we kept the $10 \times 10-\mathrm{km}^{2}$ grid cells having a field

457 plot sampling area $\geq$ to 10 ha and where the selected taxa represented at least $75 \%$ of

458 the total number of individuals originally inventoried to ensure that our dataset was

459 representative of the within-cell tree community composition. The final dataset contains 
$4606.1 \times 10^{6}$ tree individuals belonging to 193 taxa, of which 96 were analyzed at the

461 species and 97 at the genus levels (Table S2), recorded in 185,665 plots aggregated in

$4621,57110 \times 10-\mathrm{km}^{2}$ grid cells. Overall, the selected taxa represented $90 \%$ of the total

463 number of individuals originally inventoried in the selected grid cells.

464 For each taxon, we compiled information on three important functional traits. First, we

465 extracted an average wood density using the global wood density database ${ }^{55,56}$ as well

466 as other wood density data ${ }^{57}$. Wood density is an integrative trait that reflects a trade-off

467 between tree growth potential and mortality risk ${ }^{28}$ and is thus highly informative on

468 community dynamics ${ }^{58}$. It ultimately directly impacts the amount of carbon that can be

469 stored in the vegetation ${ }^{59}$. Second, we extracted the leaf phenology (deciduous or

470 evergreen) of all taxa from the large unpublished CoForTraits database ${ }^{60}$. This database

471 compiles information on more than 1000 species from central Africa with values

472 extracted from the literature (mostly from local floras, academic papers and unpublished

473 theses). When several values were available for a given species from different sources,

474 we attributed the one with the maximum of occurrences (ambiguities were left as

475 unknown). At the genus level, we first computed this step for all species belonging to

476 the genus and then attributed the phenology with the maximum of occurrences at the

477 species level to the genus so that all congeneric species have the same weight in the

478 phenology attribution. This approach relies on the assumption that leaf phenological

479 traits are highly phylogenetically conserved ${ }^{61}$. For a few taxa $(n=5)$, the phenology

480 information was obtained from Ouédraogo et al. ${ }^{30}$ and following these authors we

481 considered Lophira alata Banks ex C. F. Gaertn. and Musanga cecropioides R. Br. as

482 leaf exchangers, i.e., with a trait value of 0.5 , intermediate between evergreen ( 0 ) and

483 deciduous (1). Leaf phenology is one of the few traits considered in dynamic global

484 vegetation models as it impacts the dynamics of forest productivity ${ }^{62}$. In particular,

485 deciduousness indicates that tree photosynthetic activity, and thus growth, is seasonally

486 depressed, which has a direct impact on carbon, water and nutrient cycling ${ }^{63}$.

487 Deciduousness has often been interpreted as a strategy to avoid water stress and is 488 thus expected to depend on climate and soil conditions ${ }^{30,64}$. Lastly, we used the original 
489 inventory data to calculate the maximum diameter as the 95th percentile value of the 490 diameter distribution for each taxon. Maximum potential diameter, which is often used

491 as a proxy of maximum height ${ }^{65}$, informs both on tree competitive ability for light and on

492 the carbon sequestration potential. At the community level, it is expected to vary along

493 gradients of productivity and disturbance ${ }^{66}$. Leaf phenology was successfully assigned

494 to $89 \%$ of the taxa (98\% of the individuals), wood density to $91 \%$ of the taxa (96\% of the

495 individuals) and maximum diameter to all taxa.

\section{Climate and soil data}

497 We considered 24 climatic predictors derived from the open Climatic Research Unit 498 (CRU) dataset ${ }^{67}$ (Extended Data Table 2). We decided to rely on the CRU dataset as 499 other datasets, such as WorldClim ${ }^{68}$, contain erroneous observations for some climatic 500 stations (e.g., Ngoundi in Cameroon) that severely impacted our model. Furthermore, 501 our cross-validation approach showed that the CRU database led to higher correlations 502 between observed and predicted taxa abundances, correspondence analyses scores 503 and community weighted trait values than the WorldClim ${ }^{68}$ and CHIRPS ${ }^{69}$ databases 504 (results not shown).

505 Soil maps have been published at the country scale in central Africa and their 506 homogenization is very challenging. We thus relied on a global dataset, the Harmonized 507 World Soil Database (HWSD) ${ }^{70}$, to attribute a soil type to each grid cell. A cross-

508 validation analysis of our joint distribution model revealed that soil significantly improved 509 predictions, mostly due to the contrast between Arenic Acrisols and the other soil types

510 (Fig. S5). To keep the model parsimonious and maximize its robustness, we thus

511 merged all soil categories but the Arenic Acrisols soils into a single category and

512 discarded the permanently flooded areas as mapped in the open ESA-CCI landcover

513 product (V.1.6), where no tree inventory data were available.

\section{Human-induced forests disturbance intensity}

515 Many studies have attempted to spatialize human impacts on environment at a large 516 scale. In most cases, these human footprint maps have consisted of cumulative threat 
517 maps, assuming for instance population density and infrastructure effects ${ }^{71-73}$.

518 Moreover, most of these maps relied on population statistics obtained at the level of

519 administrative entities, resulting in human footprint indices with sharp changes at

520 administrative boundaries ${ }^{74}$. We thus developed a statistical model to link the probability

521 for a forest pixel $i$ to be impacted by anthropogenic activities depending on human

522 population density and road proximity through nonlinear relationships. This resulted in a

523 spatially continuous index representing human-induced forest disturbance intensity that

524 can be projected in space and/or time following predefined human population dynamics

525 scenarios (Extended Data Fig. 8).

526 We calibrated this index with the "Settlement Points" dataset produced under the

527 "Global Rural Urban Mapping Project" (Grumpv1). This dataset provides estimates of

528 human population (counts, in persons) for the year 2000 using a proportional allocation

529 gridding algorithm (1-km² grid) based on more than 1,000,000 national and subnational

530 geographic units. Focusing on central Africa, we compared this product with the Natural

531 Earth Populated Places product (version 3.0.0;

532 http://www.naturalearthdata.com/downloads/10m-cultural-vectors/10m-populated-

533 places/; last access the 07/10/2018) derived from the LandScan

534 (https://earthworks.stanford.edu/catalog/stanford-yj715rc4110\#iso-metadata-reference-

535 info) dataset (pixels with fewer than 200 persons per $\mathrm{km}^{2}$ were discarded). The total

536 number of populated points in central Africa (longitude 5.6 to 39.8, latitude -9.8 to 7.5 in

537 decimal degrees) was 807 and 376 for the Grumpv1 and Natural Earth products,

538 respectively. We thus performed a random manual check of the populated places

539 present in Grumpv1 and absent from Natural Earth (the reverse rarely occurred) using

540 Google Earth images and found that in all cases Grumpv1 was correct. We thus finally

541 used the Grumpv1 dataset, which mostly provides information on populated places with

542 more than ca. 1000 people. Because smaller populations may have a significant impact

543 on forests, we added to this dataset the populated locations of the category "towns"

544 from OpenStreetMap (https://data.maptiler.com/downloads/planet/\#1.59/-17.3/19.7; last

545 access $02 / 10 / 2018$ ) assuming by default that they all contained 500 people

546 (OpenStreetMap does not provide systematic information on population size). 
547 The road network was extracted from the Global Roads Open Access Data Set, version

5481 (https://data.maptiler.com/downloads/planet/\#1.59/-17.3/19.7; last access the

$54914 / 09 / 2018$ ) a dataset combining road data by country. Note that logging roads are not

550 fully represented in this dataset, so we may underestimate their effect in this study. A

551 few roads from the northern Republic of Congo were corrected using data from

552 OpenStreetMap. Preliminary analyses revealed that further accounting for the railway

553 and river networks did not improve predictions of tree taxon and community

554 distributions.

555 Our index was thus calculated as followed. Let $z_{i}, i=1, \ldots, n$ be $n$ random variables

556 indicating the disturbance status of pixel $i: 0$ if the pixel is undisturbed and 1 if disturbed.

557 We assumed that $z_{i}$ is distributed as a Bernoulli variable: $z_{i}=\operatorname{Bern}\left(p_{i}\right)$ with $p_{i}=\frac{I P_{i}(\theta)}{I P_{i}(\theta)+I R_{i}^{r}}$

558 where $I P_{i}(\theta)$ is a synthetic index describing the influence of the population density of all

559 populated places on pixel $i$ (see below), $\theta$ is an unknown parameter to be inferred, and

$560 I R_{i}^{r}$ expresses the road influence on pixel $i$, defined as the normalized square root

561 distance of pixel $i$ to the nearest road $r$ :

562

$I R_{i}^{r}=\frac{\min _{r \in R} \sqrt{D R_{i}^{r}}}{\max _{i=1, \ldots, n}\left(\min _{r \in R} \sqrt{D R_{i}^{r}}\right)}$

563

564 where $D R$ denotes the distance to the nearest road in the study area and $R$ denotes all 565 roads in the study area.

566 Population influence, $I P_{i}^{\theta}$, is defined as the normalized square root of the weighted sum

567 of the population size of place $j$. Note that the weight depends on both the distance

568 between pixel $i$ and populated place $j, \delta_{i j}$, and on the population size $N_{j}$ : 
$I P_{i}^{\theta}=\frac{\sqrt{\sum_{j}^{n} N_{j} e^{-\frac{\delta_{i j}}{\log \left(N_{j}\right)^{\theta}}}+1}}{\max \sqrt{\sum_{j}^{n} N_{j} e^{-\frac{\delta_{i j}}{\log \left(N_{j}\right)^{\theta}}}+1}}$

570 We finally calibrated the $\theta$ parameter using two reference areas of ca. $190,000 \mathrm{~km}^{2}$ (Fig.

571 S6). These two areas were chosen because they cover contrasting conditions, are well

572 known by our team and were found to be little influenced by atmospheric pollution in the

573 MODIS data. Degraded versus intact forests were identified from a recently published

574 MODIS-based regional vegetation map ${ }^{20}$. Using a likelihood optimization approach in

575 these two areas, we obtained $\theta=1.27$ and 1.71 in calibration areas 1 and 2, respectively,

576 indicating that under a similar anthropogenic context, forests tend to be disturbed at a

577 greater distance from anthropogenic disturbance sources in the second calibration area.

578 The final human-induced forest disturbance intensity index was thus calculated with $\theta$

$579=1.49$, the average estimate for the two calibration areas, over the whole central African

580 forest domain, thus avoiding the risk of artefacts related to atmospheric pollution from

581 which suffer satellite products, especially over Gabon.

582 This index, built independently from our floristic dataset, outperformed previously

583 published indices to predict floristic composition in our study area. Using a simple linear

584 model, with individual anthropogenic indices as single predictors, the mean wood

585 density of tree communities was better predicted with our new index ( $r=0.33)$ than with

586 the WorldPop ${ }^{75}(r=0.30)$, LandScan $(r=0.15)$ and $\operatorname{Venter}^{72}(r=0.23)$ indices. Similarly,

587 using a simple generalized linear model with a Poisson distribution to predict the

588 abundance of Musanga cecropioides, the most widespread and abundant short-lived

589 pioneer taxon over central African forests, revealed a better performance of our index

$590 \quad(r=0.35)$ compared to previous indices $(r=0.31,0.11,0.26$ for WorldPop, LandScan and

591 Venter, respectively).

\section{Statistical model}


593 To predict the joint taxa distributions we relied on a recently developed methodology 594 called supervised component generalized linear regression (SCGLR) ${ }^{17}$, which identifies

595 the most predictive dimensions among a large set of potentially multicollinear predictors.

596 SCGLR is an extension of partial least-squares regression (PLSR) to the uni- and

597 multivariate generalized linear framework. PLSR is particularly well suited for analyzing

598 a large array of correlated predictor variables, and many studies have demonstrated its

599 ability for prediction in various biological fields, such as genetics ${ }^{76}$ or ecology ${ }^{77}$. While

600 PLSR is well adapted for continuous variables, SCGLR is suited for non-Gaussian

601 outcomes and noncontinuous covariates. It is a model-based approach that extends

$602 \mathrm{PLSR}^{78}$, PCA on instrumental variables ${ }^{79}$, canonical correspondence analysis ${ }^{80}$, and

603 other related empirical methods by maximizing a trade-off between goodness of fit of

604 the model and the quantity of information the components capture from the climatic 605 variables. This information is measured through an indicator of "structural relevance" $606(\mathrm{SR})^{81}$, which uses bundles of highly correlated variables to attract components to rich 607 and robust informational dimensions.

608 The components are sought as $K$ linear combinations of environmental variables

609 common to all species with coefficient vectors denoted $u=\left(u_{1}, \ldots, u_{K}\right)$ (under norm and

610 orthogonality constraints). SCGLR also estimates the corresponding $q \times K$ (number of

611 species by number of components) matrix of unknown parameters $\gamma$ to maximize the

612 following convex sum:

$613 s \log \psi(u, \gamma)+(1-s) \log \phi_{l}(u)$

614 where $\psi$ is the likelihood and $\phi_{l}$ is the SR. $s$ and $l$ are tuning parameters. $s$ is related to 615 the trade-off between goodness of fit and structural relevance. $l$ is a nonnegative scalar 616 related to the narrowness of the bundles of climatic variables the components are

617 wanted to align with. The $K$ climatic components (CCs) are then equal to

$618 C C_{k}=X u_{k}, k=1, \ldots, K$ and can be understood as the main environmental directions 619 predicting all species simultaneously, while $\gamma_{j}, j=1 \ldots, q$ are the magnitude of the effects

620 of the $K$ components on the abundances of each species. Then, the species 
621 abundances of each taxon $j=1,, 193$ on the grid cell $i=1,, 1571$ are modeled using a 622 generalized linear Poisson regression such that:

$623 y_{i j} \sim P\left(S_{i} \lambda_{i j}\right)$

$624 \log \left(\lambda_{i j}\right)=X_{i} \beta_{j}+T_{i} \alpha_{j}=X_{i} u \gamma_{j}+T_{i} \alpha_{j}=C C_{i} \gamma_{j}+T_{i} \alpha_{j}$

625 where $X$ denotes climatic variables (Extended data Table 2), $S_{i}$ is an offset

626 corresponding to the number of plots within each grid cell, and $T$ is a set of covariates

627 known to impact species abundances: here, the soil type and the human-induced forest

628 disturbance intensity index, as well as its logarithm to account for nonlinear responses.

629 The number of components $(K)$ as well as the tuning parameters ( $l$ and $s$ ) must

630 appropriately be chosen. This was done with a $10 \%$ cross-validation procedure in which

631 the criterion used was the harmonic mean of the mean square prediction error (MSPE)

632 across the 194 taxa. A dedicated R package, SCGLR ${ }^{82}$, is available (see also

633 https://github.com/SCnext/SCGLR).

634 To assess the predictive power of our model, we performed a leave-one block out

635 cross-validation in which our dataset was divided into 40 spatial clusters identified with a 636 Ward's hierarchical clustering ${ }^{83}$ of plot coordinates (Fig. S7). All clusters but one were

637 used for training the model (i.e., calibration dataset) and the remaining cluster was used

638 for validating the model. We repeated this procedure 40 times such that all clusters

639 were used once in the validation dataset and participated in the model assessment.

640 Model validation was performed through the use of the nonparametric Spearman's rank

641 correlation coefficients between observations and predictions. For individual taxon

642 abundances, correlations were estimated using observed and predicted abundance per

643 taxon. For taxon assemblages, a correspondence analysis (CA) was performed on the

644 grid cell $\times$ observed species abundance matrix, providing the observed CA axes. The

645 predicted site scores on each CA axis were then obtained by projecting the grid cell $\times$

646 predicted species abundance matrix in the observed CA planes. Correlations were

647 computed on the observed and predicted site scores (i.e., loadings) enabling us to

648 assess the ability of our model to predict the main floristic gradients across our area. 
649 Finally, for the three functional traits, correlations were estimated on the grid cell-based 650 community weighted mean (CWM) traits ${ }^{27}$ calculated on observed and predicted taxon

651 assemblages.

652 Taxon abundances and community composition were predicted across the entire study 653 area in a regular 10-km grid. To predict the floristic composition of the existing forests, 654 we first used the ESA-CCI landcover product (V.1.6) to only keep grid cells that are 655 likely to be forested (i.e., category "broadleaved evergreen"). Then, we only selected 656 grid cells that had a combination of predictor values similar to those in the calibration

657 dataset. To do this, we used a 3-dimensional convex hull algorithm on the three climatic 658 components to exclude all the grid cells that had a combination of predictors different 659 from that represented in the calibration dataset. This resulted in 12,295 grid cells, 660 representing $85 \%$ of the central African forests, i.e., an area of ca. 1,230,000 km².

661 We finally used the Ward's hierarchical clustering method to classify the predicted 662 floristic composition into broad floristic types. Group classification was done on the first

663 five axes of a CA performed on predicted taxon abundances, accounting for $77 \%$ of the 664 total inertia. The number of retained types was chosen based on our expert knowledge.

665 The uncertainty associated with this classification was then assessed through Gaussian 666 finite mixture models ${ }^{84}$ (repeated 500 times) using a spherical, equal volume model 667 (EII).

\section{Spatially explicit null models}

669 Whenever predictors and observations are spatially structured, model errors of type I

670 (false positive associations) are inflated ${ }^{85}$, hindering our capacity to extrapolate

671 predictions in space or time ${ }^{22}$. We thus built a spatialized null model to test the degree

672 to which the successfulness of our predictions resulted from an actual relationship with 673 climatic variables or was simply due to spatial costructures between taxon distributions 674 and climatic gradients that arose by chance. We used the RGEOSTAT R package ${ }^{86}$ to 675 simulate sets of SCGLR climatic components (CCs) having similar spatial properties to 676 those of the observed CCs as well as similar spatial costructures between them. This 677 step consisted of fitting theoretical variograms and covariograms to empirical ones to 
678 simulate random realizations that can be then used as "null" spatialized predictors (Fig.

679 S8 and S9). We simulated 500 sets of "null" spatialized predictors and used them as

680 predictors in our GLMs using the leave-one block out cross-validation described above.

681 The resulting correlations between observed and predicted taxon abundances, and

682 axes scores (for taxon assemblages) were finally compared with the correlations

683 obtained when observed climatic predictors were considered. The resulting p-values

684 were calculated as the number of times a simulated correlation was higher than the

685 observed one, divided by the total number of realizations $(n=501)$.

\section{Forest vulnerability to global change}

687 Vulnerability to climate change, as assessed through the IPCC framework, is composed 688 of three components: (1) sensitivity, (2) exposure, and (3) adaptive capacity to climate 689 change.

690 Sensitivity to climate change, Sen sitivit $y_{\text {clim }}$, was firstly estimated at the taxon level in 691 a similar way to Foden et al. ${ }^{34}$. For each taxon, we calculated the mean of the weighted 692 standard deviation ( $S D w$ ) of the three climatic components (CCs) at the present time, 693 using locally observed taxon abundances as weights. $S D w$ thus represents the width of 694 the climatic niche currently occupied by the taxa. Taxon-specific climate sensitivity was 695 then measured as $1 / \overline{S D w}$ (it increases as niche width decreases). To upscale tree 696 sensitivity to climate change at the community level and over our study area, sensitivity 697 was measured as the community weighted mean ( $C W M)$ of taxon-specific climate 698 sensitivity scores, using predicted taxon assemblages.

699 Exposure to climate change, Ex posure $e_{c l i m}$, was assessed using projected changes in 700 climate from 18 unique climate model combinations provided by the AFRICLIM V3.0 701 dataset $^{87}$ (last access on 03/02/2020). These models corresponded to pairwise 702 combinations of five regional climate models (RCMs) driven by ten general circulation 703 models (GCMs), with an unequal number of GCMs models per RCM (ten models for the 704 Swedish Meteorological and Hydrological (SMHI) RCM, four for the Climate Limited705 area Modelling Community (CLMCOM) RCM, two for the Royal Netherlands 
706 Meteorological Institute (KNMI) RCM, one for the Canadian Centre for Climate

707 Modelling (CCCMA) RCM and one for the Danish Meteorological Institute (DMI) RCM).

708 These models were generated using change-factor downscaling approaches to model

709 spatial variation at local scales while correcting for differences between observed and

710 simulated baseline climates (see Platts et al. ${ }^{87}$ for more details). We here concentrated

711 on one representative concentration pathway of the IPCC-AR5 (RCP 4.5) for the late

712 21st century (2071-2100, hereafter named 2085) and reconstructed the three SCGLR

713 selected CCs from the climatic predictions as follows: let $X_{\text {rcp } 4.5}$ be the predicted future

714 climatic conditions. Let $m=\bar{X}$ and $S=s d(X)$ be the mean and standard deviation matrices

715 of the current climatic conditions. The predictive climatic components under future

716 scenarios are then equal to $f_{r c p 4.5}=\left(X_{r c p 4.5}-m\right) S \hat{u}$, where $\hat{u}$ represents SCGLR CCs. We

717 then calculated the euclidean distance between the three current and the three

718 predicted CCs for each of the 18 models and then estimated the exposure to climate

719 change as the mean distance over the 18 models.

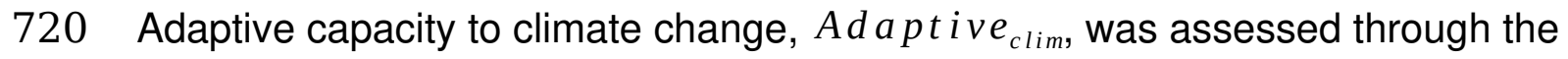

721 phylogenetic diversity of predicted assemblages at the genus level. We used a recently

722 published dated phylogeny ${ }^{88}$, covering 167 out of our 180 genera (representing $94 \%$ of

723 predicted individuals). We first tested if the studied taxa exhibited a significant

724 conservatism in their climate niches using Abouheif's permutation tests (Abouheif,

725 1999) on the taxa-specific score $(\gamma)$ values on the three SCGLR climate components $(\gamma$

726 represents the influence of a CC on a given taxa distribution, see above). We then

727 measured the phylogenetic diversity (PD) of predicted assemblages at the genera level

728 using the Chao's PD index with an order q of 1 (equivalent to the Shannon index) ${ }^{89}$ that

729 we used as a proxy of adaptive capacity.

730 Vulnerability to climate change, Vulne rabilit $y_{\text {clim }}$, was finally estimated as the sum of

731 the three standardized ( 0 to 1 ) components:

732 Vulnerabilit $y_{\text {clim }}=\left(\right.$ Sensitivit $y_{\text {clim }}^{\text {st }}+$ Ex posur $e_{\text {clim }}^{\text {st }}-$ Ada ptive $\left.e_{c l i m}^{\text {st }}\right)$.

733 Vulne rabilit $y_{\text {clim }}$ theoretically ranges from -1 (low vulnerability) to 2 (high 
734 vulnerability) and, due to the standardization of its three components, it expresses a

735 relative vulnerability over the study area and is thus little impacted by the IPCC scenario

736 chosen (RCP 4.5 or 8.5 ) because different scenarios predict different amplitudes of

737 changes but similar spatial patterns (Extended Data Fig. 7).

738 Forecasted human impact on forests in 2085 was assessed using our human-induced

739 forest disturbance intensity index combined with country-specific projections of human

740 populations in 2085 . We assigned to each current town a country-specific relative

741 population increase drawn from the World population prospects (United Nations) ${ }^{90}$ and

742 rebuild our index based on this modified dataset. This approach did not account for new

743 roads that may established by 2085 , and thus tended to underestimate the increase in

744 anthropogenic pressure.

\section{Software and packages}

746 All analyses were performed and figures were created with the $\mathrm{R}$ statistical software ${ }^{91}$,

747 mostly using the ade $4^{92}$, alphashape $3 d^{93}$, ggplot $2^{94}$, raster $^{95}$, RgeoStat ${ }^{96}$, entropart ${ }^{97}$ and

748 SCGLR (https://github.com/SCnext/SCGLR/) packages. Data are archived in a public

749 repository $^{98}$.

\section{Data availability}

751 All maps and data used for this article are accessible online in a public repository at

752 http://dx.doi.org/10.18167/DVN1/UCNCA7. Raw floristic data are, however, archived in

753 a private data repository, due to the highly sensitive nature of commercial inventory

754 data, and access may be granted for research purpose using the form provided in the

755 public repository.

756 Code availability

757 R scripts are available at https://github.com/MaximeRM/ScriptNature.

\section{Methods references}


759 51. Réjou-Méchain, M. et al. Detecting large-scale diversity patterns in tropical trees:

760 Can we trust commercial forest inventories? Forest Ecology and Management 261,

761 187-194 (2011).

762 52. Chase, M. W. et al. An update of the Angiosperm Phylogeny Group classification for 763 the orders and families of flowering plants: APG III. Botanical Journal of the Linnean 764 Society 161, 105-121 (2009).

765 53. Dauby, G. et al. RAINBIO: A mega-database of tropical African vascular plants 766 distributions. PhytoKeys 1 (2016).

767 54. African Plant Database (version 3.4.0). Conservatoire et Jardin botaniques de la 768 Ville de Genève and South African National Biodiversity Institute, Pretoria. Retrieved the 769 10/02/2017.

770 55. Chave, J. et al. Towards a worldwide wood economics spectrum. Ecology Letters 771 12, 351-366 (2009).

772 56. Zanne, A. E. et al. Global wood density database. Dryad. Identifier: http://hdl.

773 handle. net/10255/dryad 235, (2009).

774 57. Gourlet-Fleury, S. et al. Environmental filtering of dense-wooded species controls 775 above-ground biomass stored in African moist forests. Journal of Ecology 99, 981-990 776 (2011).

777 58. Westoby, M. \& Wright, I. J. Land-plant ecology on the basis of functional traits.

778 Trends in Ecology \& Evolution 21, 261-268 (2006).

779 59. Chave, J. et al. Improved allometric models to estimate the aboveground biomass of 780 tropical trees. Global Change Biology 20, 3177-3190 (2014).

781 60. Bénédet, F. et al. CoForTraits, African plant traits information database . Version 782 1.0. (2013). 
783 61. Davies, T. J. et al. Phylogenetic conservatism in plant phenology. Journal of ecology 784 101, 1520-1530 (2013).

785 62. Cramer, W. et al. Global response of terrestrial ecosystem structure and function to $786 \mathrm{CO} 2$ and climate change: Results from six dynamic global vegetation models. Global 787 change biology $7,357-373$ (2001).

788 63. Menzel, A. Phenology: Its importance to the global change community. Climatic 789 change 54, 379 (2002).

790 64. Borchert, R., Rivera, G. \& Hagnauer, W. Modification of Vegetative Phenology in a 791 Tropical Semi-deciduous Forest by Abnormal Drought and Rain 1. Biotropica 34, 27-39 792 (2002).

793 65. Kraft, N. J. B., Valencia, R. \& Ackerly, D. D. Functional traits and niche-based tree 794 community assembly in an amazonian forest. Science 322, 580-582 (2008).

795 66. Schamp, B. S. \& Aarssen, L. W. The assembly of forest communities according to 796 maximum species height along resource and disturbance gradients. Oikos 118, 564797572 (2009).

798 67. New, M., Lister, D., Hulme, M. \& Makin, I. A high-resolution data set of surface 799 climate over global land areas. Climate research 21, 1-25 (2002).

800 68. Hijmans, R. J., Cameron, S. E., Parra, J. L., Jones, P. G. \& Jarvis, A. Very high 801 resolution interpolated climate surface for global land areas. International journal of 802 climatology 25, 1965-1978 (2005).

803 69. Funk, C. et al. The climate hazards infrared precipitation with stations-a new 804 environmental record for monitoring extremes. Scientific data 2, 150066 (2015).

805 70. Nachtergaele, F. et al. The harmonized world soil database. in Proceedings of the 806 19th World Congress of Soil Science, Soil Solutions for a Changing World, Brisbane, 807 Australia, 1-6 August 2010 34-37 (2010). 
808 71. Woolmer, G. et al. Rescaling the human footprint: A tool for conservation planning at 809 an ecoregional scale. Landscape and Urban Planning 87, 42-53 (2008).

810 72. Venter, O. et al. Sixteen years of change in the global terrestrial human footprint and

811 implications for biodiversity conservation. Nature Communications 7, 12558 (2016).

812 73. Geldmann, J., Joppa, L. N. \& Burgess, N. D. Mapping change in human pressure

813 globally on land and within protected areas. Conservation biology 28, 1604-1616

814 (2014).

815 74. Linard, C., Gilbert, M., Snow, R. W., Noor, A. M. \& Tatem, A. J. Population

816 distribution, settlement patterns and accessibility across Africa in 2010. PloS one 7,

817 e31743 (2012).

818 75. Lloyd, C. T. et al. Global spatio-temporally harmonised datasets for producing high-

819 resolution gridded population distribution datasets. Big Earth Data 3, 108-139 (2019).

820 76. Boulesteix, A.-L. \& Strimmer, K. Partial least squares: A versatile tool for the

821 analysis of high-dimensional genomic data. Briefings in bioinformatics 8, 32-44 (2007).

822 77. Carrascal, L. M., Galván, I. \& Gordo, O. Partial least squares regression as an

823 alternative to current regression methods used in ecology. Oikos 118, 681-690 (2009).

824 78. Tenenhaus, M. La régression PLS: Théorie et pratique. (Editions Technip, 1998).

825 79. Sabatier, R., Lebreton, J. D. \& Chessel, D. Principal component analysis with

826 instrumental variables as a tool for modelling composition data. Multiway data analysis

827 341-352 (1989).

828 80. Ter Braak, C. J. The analysis of vegetation-environment relationships by canonical

829 correspondence analysis. in Theory and models in vegetation science 69-77 (Springer, 830 1987).

831 81. Bry, X. \& Verron, T. THEME: THEmatic model exploration through multiple co-

832 structure maximization. Journal of Chemometrics 29, 637-647 (2015). 
833 82. Cornu, G., Mortier, F., Trottier, C. \& Bry, X. SCGLR: Supervised Component

834 Generalized Linear Regression. (2016).

835 83. Ward Jr, J. H. Hierarchical grouping to optimize an objective function. Journal of the 836 American statistical association 58, 236-244 (1963).

837 84. Scrucca, L., Fop, M., Murphy, T. B. \& Raftery, A. E. Mclust 5: Clustering, 838 classification and density estimation using gaussian finite mixture models. The $R$ journal 839 8, 289 (2016).

840 85. Dormann, C. F. et al. Methods to account for spatial autocorrelation in the analysis

841 of species distributional data: A review. Ecography 30, 609-628 (2007).

842 86. Renard, D. et al. RGeostats: The Geostatistical package 11.0. 1. MINES ParisTech 843 (2014).

844 87. Platts, P. J., Omeny, P. A. \& Marchant, R. AFRICLIM: High-resolution climate 845 projections for ecological applications in Africa. African Journal of Ecology 53, 103-108 846 (2015).

847 88. Janssens, S. B. et al. A large-scale species level dated angiosperm phylogeny for 848 evolutionary and ecological analyses. Biodiversity data journal 8, (2020).

849 89. Chao, A., Chiu, C.-H. \& Jost, L. Phylogenetic diversity measures based on Hill

850 numbers. Philosophical Transactions of the Royal Society B: Biological Sciences 365,

$8513599-3609$ (2010).

852 90. Nations, U. World population prospects: The 2017 revision, key findings and 853 advance tables. United Nations, New york (2017).

854 91. R Core Team. R: A language and environment for statistical computing. ( $\mathrm{R}$ 855 Foundation for Statistical Computing, 2017).

856 92. Chessel, D., Dufour, A. B. \& Thioulouse, J. The ade4 package-I- One-table 857 methods. R News 7, 47-52 (2004). 
858 93. Lafarge, T. \& Pateiro-Lopez, B. Alphashape3d: Implementation of the 3D alpha-

859 shape for the reconstruction of 3D sets from a point cloud. (2017).

860 94. Wickham, H. Ggplot2: Elegant graphics for data analysis. (Springer-Verlag New

861 York, 2016).

862 95. Hijmans, R. J. Raster: Geographic data analysis and modeling. (2017).

863 96. Renard, D. et al. RGeostats: Geostatistical package. (2017).

864 97. Marcon, E. \& Hérault, B. entropart: An R package to measure and partition diversity.

865 Journal of Statistical Software 67, 1-26 (2015).

866 98. Réjou-Méchain, M. et al. Maps of central African rainforest composition and

867 vulnerability, doi:10.18167/DVN1/UCNCA7, CIRAD Dataverse, V2, (2021).

868

869

\section{Acknowledgements}

871 We thank the 105 forest companies that provided access, albeit restricted, to their

872 inventory data for research purposes and members of the central african plot network

873 (https://central-african-plot-network.netlify.app/), Y. Yalibanda, F. Allah-Barem, F. Baya,

874 F. Boyemba, M. Mbasi Mbula, P. Berenger, M. Mazengue, V. Istace, I. Zombo, E. Forni,

875 Nature+ and the CEB-Precious Woods company for giving access to the scientific

876 inventories described in Fig. S4, some of which were funded by the AFD and the FFEM

877 (e.g. DynAfFor and P3FAC projects). We thank J. Chave, P. Couteron, S. Lewis and M.

878 Tadesse for their helpful comments and discussions on previous versions. We also

879 thank the five reviewers for their highly constructive comments on previous versions, $B$.

880 Sultan for useful discussions on climate projections, O.J. Hardy for advices on

881 phylogenetical analyses, B. Locatelli for advices on vulnerability analyses, G. Vieilledent

882 for our discussions on the human-induced forest disturbance intensity index and $A$.

883 Stokes for English editing. This work was supported by the CoForTips project (ANR-12- 
884 EBID-0002) funded by the ERA-NET BiodivERsA, with the national funders ANR, 885 BELSPO and FWF, as part of the 2012 BiodivERsA call for research proposals, the 886 GAMBAS project funded by the French National Research Agency (ANR-18-CE02887 0025) and the project 3DForMod funded by the UE FACCE ERA-GAS consortium 888 (ANR-17-EGAS-0002-01). This study is a contribution to the research program of LMI 889 DYCOFAC (Dynamique des écosystèmes continentaux d'Afrique Centrale en contexte 890 de changements globaux).

891 Author contributions,

892 Conceptualization: M.R-M., F.M., R.P. \& S.G-F; data curation: G.C. \& F.B.; formal 893 analysis: M.R-M. \& F.M.; project administration: C.G.; writing - original draft: M.R-M., 894 F.M., R.P. \& S.G-F; writing - review \& editing: all authors.

895 Competing interests

896 Authors declare no competing interests.

897 Supplementary Information is available for this paper

898 Correspondence and requests for materials should be addressed to

899 maxime.rejou@ird.fr

900 Reprints and permissions information is available at www.nature.com/reprints

901

902 


\section{Extended data figure/table legends:}

\begin{tabular}{|c|c|c|c|c|c|c|c|c|c|c|}
\hline Group & Name & Main families & Representative taxa & Area & PA & Logging & Phum & $\mathrm{CC} 1$ & $\mathrm{CC} 2$ & CC3 \\
\hline 1 & $\begin{array}{l}\text { Atlantic highland } \\
\text { evergreen }\end{array}$ & $\begin{array}{l}\text { Fabaceae }(19 \%), \\
\text { Burseraceae }(17 \%) \text {, } \\
\text { Myristicaceae }(13 \%)\end{array}$ & $\begin{array}{l}\text { Anisophyllea spp., Baillonella toxisperma, } \\
\text { Aucoumea klaineana, Bobgunnia fistuloides, } \\
\text { Testulea gabonensis }\end{array}$ & 79,400 & 9 & 70 & 0.48 & -3.4 & 3.4 & -1.1 \\
\hline 2 & $\begin{array}{l}\text { Atlantic coastal } \\
\text { evergreen }\end{array}$ & $\begin{array}{l}\text { Fabaceae }(27 \%) \text {, } \\
\text { Burseraceae }(17 \%) \text {, } \\
\text { Myristicaceae }(15 \%)\end{array}$ & $\begin{array}{l}\text { Anthostema aubryanum, Scytopetalum } \\
\text { klaineanum, Calpocalyx spp., Coula edulis, } \\
\text { Tetraberlinia bifoliolata }\end{array}$ & 17,700 & 54 & 36 & 0.35 & -5.2 & 0.1 & 4.6 \\
\hline 3 & $\begin{array}{l}\text { Atlantic inland } \\
\text { evergreen }\end{array}$ & $\begin{array}{l}\text { Fabaceae }(27 \%) \text {, } \\
\text { Burseraceae }(15 \%) \text {, } \\
\text { Myristicaceae }(14 \%)\end{array}$ & $\begin{array}{l}\text { Calpocalyx spp., Letestua durissima, } \\
\text { Eurypetalum spp., Coula edulis, Tetraberlinia } \\
\text { bifoliolata }\end{array}$ & 60,800 & 22 & 69 & 0.35 & -3.8 & -0.1 & 3.0 \\
\hline 4 & $\begin{array}{l}\text { Margin } \\
\text { semideciduous }\end{array}$ & $\begin{array}{l}\text { Malvaceae }(16 \%) \\
\text { Fabaceae }(13 \%) \\
\text { Cannabaceae }(11 \%)\end{array}$ & $\begin{array}{l}\text { Aubrevillea kerstingii, Holoptelea grandis, } \\
\text { Mansonia altissima, Trilepisium } \\
\text { madagascariense, Morus mesozygia }\end{array}$ & 87,600 & 4 & 20 & 0.42 & 4.1 & 2.4 & 2.0 \\
\hline 5 & $\begin{array}{l}\text { Evergreen- } \\
\text { semideciduous } \\
\text { on sandstone }\end{array}$ & $\begin{array}{l}\text { Fabaceae }(15 \%) \\
\text { Sapotaceae }(15 \%) \\
\text { Annonaceae }(9 \%)\end{array}$ & $\begin{array}{l}\text { Manilkara spp., Oldfieldia africana, Balanites } \\
\text { wilsoniana, Autranella congolensis, } \\
\text { Synsepalum spp. }\end{array}$ & 22,200 & 23 & 80 & 0.27 & 3.2 & 2.0 & 1.0 \\
\hline 6 & Semideciduous & $\begin{array}{l}\text { Fabaceae }(20 \%) \text {, } \\
\text { Annonaceae }(10 \%) \text {, } \\
\text { Malvaceae }(8 \%)\end{array}$ & $\begin{array}{l}\text { Pericopsis elata, Fernandoa adolfi friderici, } \\
\text { Dasylepis seretii, Desplatsia spp., } \\
\text { Entandrophragma cylindricum }\end{array}$ & 206,400 & 10 & 34 & 0.26 & 2.6 & -0.3 & -0.2 \\
\hline 7 & Central evergreen & $\begin{array}{l}\text { Fabaceae }(33 \%) \text {, } \\
\text { Annonaceae }(9 \%) \text {, } \\
\text { Olacaceae }(9 \%)\end{array}$ & $\begin{array}{l}\text { Millettia spp., Brachystegia spp., Ochna spp., } \\
\text { Gilbertiodendron dewevrei, Rothmannia spp. }\end{array}$ & 265,900 & 23 & 9 & 0.22 & 0.6 & -3.8 & -2.3 \\
\hline 8 & Mixed evergreen & $\begin{array}{l}\text { Fabaceae }(30 \%) \text {, } \\
\text { Olacaceae }(10 \%) \\
\text { Myristicaceae }(8 \%)\end{array}$ & $\begin{array}{l}\text { Diogoa zenkeri, Elaeis guineensis, } \\
\text { Cryptosepalum spp., Bikinia spp., } \\
\text { Ochthocosmus spp. }\end{array}$ & 158,200 & 10 & 45 & 0.40 & -1.4 & -2.2 & -0.2 \\
\hline 9 & $\begin{array}{l}\text { Degraded } \\
\text { semideciduous }\end{array}$ & $\begin{array}{l}\text { Fabaceae }(14 \%) \text {, } \\
\text { Cannabaceae }(13 \%) \text {, } \\
\text { Urticaceae }(8 \%)\end{array}$ & $\begin{array}{l}\text { Pseudospondias spp., Musanga } \\
\text { cecropioides, Pterygota spp., Ricinodendron } \\
\text { heudelotii, Afzelia spp. }\end{array}$ & 40,000 & 10 & 6 & 0.73 & 1.1 & 2.0 & 1.6 \\
\hline 10 & $\begin{array}{l}\text { Semideciduous- } \\
\text { evergreen } \\
\text { transition }\end{array}$ & $\begin{array}{l}\text { Fabaceae }(22 \%) \text {, } \\
\text { Annonaceae }(10 \%) \text {, } \\
\text { Olacaceae }(8 \%)\end{array}$ & $\begin{array}{l}\text { Uapaca spp., Musanga cecropioides, } \\
\text { Annickia spp., Croton spp., Pseudospondias } \\
\text { spp. }\end{array}$ & 180,000 & 15 & 29 & 0.37 & 0.4 & -0.3 & -1.5 \\
\hline
\end{tabular}

904

905 Extended Data Table 1 | Characteristics of the floristic groups. For each floristic

906 group information is given on the three most abundant families (APGIll classification,

907 except for the subfamilies Caesalpiniaceae and Mimosaceae, which were considered

908 here independently due to their different ecological strategies), the five most

909 representative taxa (i.e., taxa having the highest A score of the Dufrêne and Legendre

910 index), the total area ( $\mathrm{km} 2$ ) covered by each group, the percentage of the area

911 covered by protected areas (PA) and dedicated to logging activities (Logging), the mean

912 probability of being impacted by human activities (phum, this study) and the mean value

913 of the three climatic components (CCs) that best explain the current distribution of

914 central African trees (this study). 


\begin{tabular}{|c|c|c|c|c|c|}
\hline CODE & Description & Mean (range) & $\mathrm{CC} 1$ & $\mathrm{CC} 2$ & CC3 \\
\hline $\mathrm{C} 1$ & Annual Mean Temperature $\left({ }^{\circ} \mathrm{C}\right)$ & $24.7(22.7-26.4)$ & -0.01 & -0.54 & 0.43 \\
\hline $\mathrm{C} 2$ & Mean Diurnal Range ( $\left.{ }^{\circ} \mathrm{C}\right)$ & $9.4(6.2-11)$ & 0.88 & 0.01 & 0 \\
\hline C3 & Isothermality (C2/C7) $\left({ }^{*} 100\right)$ (unitless) & $76.6(53.1-89.8)$ & -0.06 & -0.67 & -0.16 \\
\hline C4 & $\begin{array}{l}\text { Temperature Seasonality (Coefficient of } \\
\text { Variation of kelvin values) (\%) }\end{array}$ & $1.5(0.7-3.6)$ & -0.21 & 0.54 & 0.08 \\
\hline C5 & Max Temperature of Warmest Month $\left({ }^{\circ} \mathrm{C}\right)$ & $31.1(28.6-33.9)$ & 0.38 & -0.03 & 0.51 \\
\hline C6 & Min Temperature of Coldest Month $\left({ }^{\circ} \mathrm{C}\right)$ & $18.8(16.5-22)$ & -0.15 & -0.76 & 0.06 \\
\hline C7 & Temperature Annual Range $(\mathrm{C} 5-\mathrm{C} 6)\left({ }^{\circ} \mathrm{C}\right)$ & $12.3(9.4-16)$ & 0.53 & 0.32 & 0.1 \\
\hline C8 & Mean Temperature of Wettest Quarter $\left({ }^{\circ} \mathrm{C}\right)$ & $24.5(22-26.6)$ & -0.21 & -0.42 & 0.27 \\
\hline C9 & Mean Temperature of Driest Quarter $\left({ }^{\circ} \mathrm{C}\right)$ & $24.2(20.9-27.2)$ & 0.3 & -0.53 & 0.13 \\
\hline C10 & Mean Temperature of Warmest Quarter $\left({ }^{\circ} \mathrm{C}\right)$ & $25.6(23.9-27.3)$ & -0.01 & -0.19 & 0.75 \\
\hline $\mathrm{C} 11$ & Mean Temperature of Coldest Quarter $\left({ }^{\circ} \mathrm{C}\right)$ & $23.8(20.5-25.5)$ & 0.08 & -0.73 & 0.14 \\
\hline C12 & Annual Precipitation $(\mathrm{mm})$ & $1733.5(1219.7-2983)$ & -0.26 & -0.06 & 0.06 \\
\hline $\mathrm{C} 13$ & Precipitation of Wettest Month (mm) & $263.2(195.7-608.7)$ & -0.43 & 0.05 & 0.11 \\
\hline C14 & Precipitation of Driest Month $(\mathrm{mm})$ & $31.9(0-112.4)$ & 0.2 & -0.4 & -0.16 \\
\hline C15 & $\begin{array}{l}\text { Precipitation Seasonality (Coefficient of } \\
\text { Variation) }(\%)\end{array}$ & $52.1(21.7-84.5)$ & -0.29 & 0.51 & 0.15 \\
\hline C16 & Precipitation of Wettest Quarter (mm) & $665(435.8-1273.7)$ & -0.28 & 0.01 & 0.15 \\
\hline C17 & Precipitation of Driest Quarter (mm) & $137.7(2-405.2)$ & 0.14 & -0.53 & -0.13 \\
\hline C18 & Precipitation of Warmest Quarter (mm) & $434.3(220.7-816.1)$ & -0.9 & 0 & 0 \\
\hline $\mathrm{C} 19$ & Precipitation of Coldest Quarter (mm) & $302.8(0.7-1332.9)$ & 0.8 & 0 & 0.02 \\
\hline meanETO & mean monthly evapotranspiration ${ }^{1}(\mathrm{~mm})$ & $133.8(109.9-146.6)$ & 0.76 & -0.1 & 0.02 \\
\hline meanCWB & mean climatic water balance ${ }^{2}(\mathrm{~mm})$ & $10.6(-19.2-134.3)$ & -0.52 & 0.01 & 0.02 \\
\hline sumCWD & total climatic water deficit ${ }^{3}(\mathrm{~mm})$ & $-1617.8(-4466.3--55.8)$ & -0.59 & -0.29 & -0.07 \\
\hline $\operatorname{maxCWD}$ & maximum cumulative water deficit $^{4}(\mathrm{~mm})$ & $-299.3(-596--21.9)$ & -0.08 & -0.6 & -0.21 \\
\hline MCWD & maximum climatic water deficit ${ }^{5}(\mathrm{~mm})$ & $-312.3(-596--37.7)$ & -0.08 & -0.62 & -0.18 \\
\hline
\end{tabular}

${ }^{1}$ meanETO was calculated using the Hargreaves formula with meanET0 $=\frac{1}{n} \sum_{i=1}^{n} E T 0_{i}$ where $E T 0_{i}$ is the evapotranspiration of month $i$ calculated as $E T 0_{i}=0.0023 * 0.408 R A_{i} *\left(T a v g_{i}+17.8\right) * T D_{i}^{0.5}$ with $R A$ the mean extrasolar radiation of month $i$ in $\mathrm{MJ} \mathrm{m} \mathrm{m}^{-2} \mathrm{~d}^{-1}$, Tavg $_{i}$ the average daily temperature of month $i$ in $\left({ }^{\circ} \mathrm{C}\right)$, computed as the average of the mean maximum and minimum temperature of month $i$ and $T D_{i}$ the mean temperature range of month $i$ in $\left({ }^{\circ} \mathrm{C}\right)$, computed as the difference between mean maximum and minimum temperature of month $i$.

${ }^{2}$ mean $C W B=\frac{1}{n} \sum_{i=1}^{n} P_{i}-E T 0_{i}$ where $P_{i}$ is the precipitation of month $i$.

${ }^{3,4} \operatorname{sum}_{C W} W=\operatorname{sum}_{i=1}^{n} C W D_{i}$ and $\max C W D=\max \left(C W D_{i}\right)$ where $C W D_{i}=\operatorname{sum}_{i=1}^{n} W D_{i}$ with $W D_{i}=W D_{i-1}+P_{i}-$ $E T 0_{i}$ if $W D_{i-1}+P_{i}-E T 0_{i}<0$ or $W D_{i}=0$ if $W D_{i-1}+P_{i}-E T 0_{i} \geq 0$. To compute $C W D_{i}$, the wettest month was set as $i=1$ at the grid cell level.

${ }^{5} M C W D=\operatorname{sum}_{i=1}^{n} \min \left(0, P_{i}-E T 0_{i}\right)$.

916

917 Extended Data Table 2 | Climatic predictors. Correlations with the three climatic

918 components (CCs) are given in the last three columns (see also Extended Data Fig. 4).

$919{ }^{1}$ meanETO was calculated using the Hargreaves formula with meanET $0=\frac{1}{n} \sum_{i=1}^{n} E T 0_{i}$

920 where $E T O_{i}$ is the evapotranspiration of month $i$ calculated as $E T O_{i}=0.0023^{*} 0.408 R A_{i}$ *

$921\left(T a v g_{i}+17.8\right)^{*} T D_{i}^{0.5}$ with $R A_{i}$ the mean extrasolar radiation of month $i$ in $\mathrm{MJ} \mathrm{m}^{-2} \mathrm{~d}^{-1}$,

$922 \mathrm{Tavg}_{i}$ the average daily temperature of month $i$ in ${ }^{\circ} \mathrm{C}$, computed as the average of the

923 mean maximum and minimum temperature of month $i$, and $T D_{i}$ the mean temperature

924 range of month $i$ in ${ }^{\circ} \mathrm{C}$, computed as the difference between mean maximum and

925 minimum temperature of month $i .{ }^{2}$ meanCWB $=\frac{1}{n} \sum_{i=1}^{n} P_{i}-E T 0_{i}$ where $P_{i}$ is the precipitation 
926 of month $i .^{3,4} \operatorname{sum} C W D=\sum_{i=1}^{n} C W D_{i}$ and $\max C W D=\max \left(C W D_{i}\right)$ where $\operatorname{sum} C W B=\sum_{i=1}^{n} C W D_{i}$

927 with $W D_{i}=W D_{i-1}+P_{i}-E T 0_{i}$ if $W D_{i}=W D_{i-1}+P_{i}-E T 0_{i}$ or $W D_{i}=0$ if $\left(W D_{i-1}+P_{i}-E T 0_{i}\right) \geq 0$. To

928 compute $C W D_{i}$, the wettest month was set as $i=1$ at the grid cell level. ${ }^{5}$

$929 M C W D=\sum_{i=1}^{n} \min \left(0, P_{i}-E T 0_{i}\right)$.

930

931 


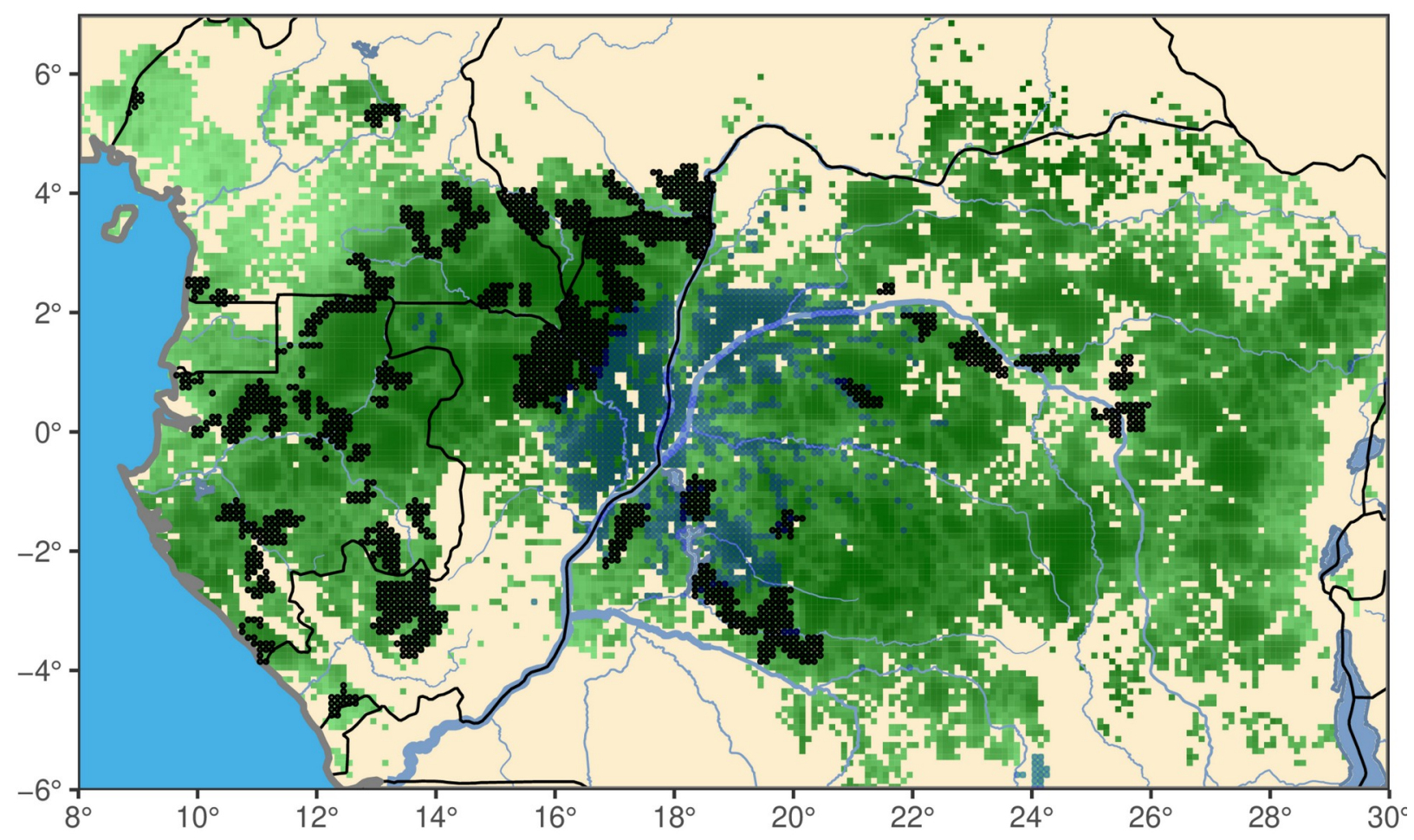

932

933 Extended Data Figure 1 | Study area and sampling plots. In green, the current

934 distribution of tropical forests following the European Space Agency Climate Change

935 Initiative (ESA-CCI) landcover (V.1.6) with a dark green-to-white gradient representing

936 anthropogenic pressure (see methods) and non-forested areas represented in beige;

937 the sampling grid cells ( $n=1,57110 \times 10-\mathrm{km}^{2}$ grid cells) are in black and the flooding

938 forests, as proposed by the ESA-CCI landcover, are in blue. 


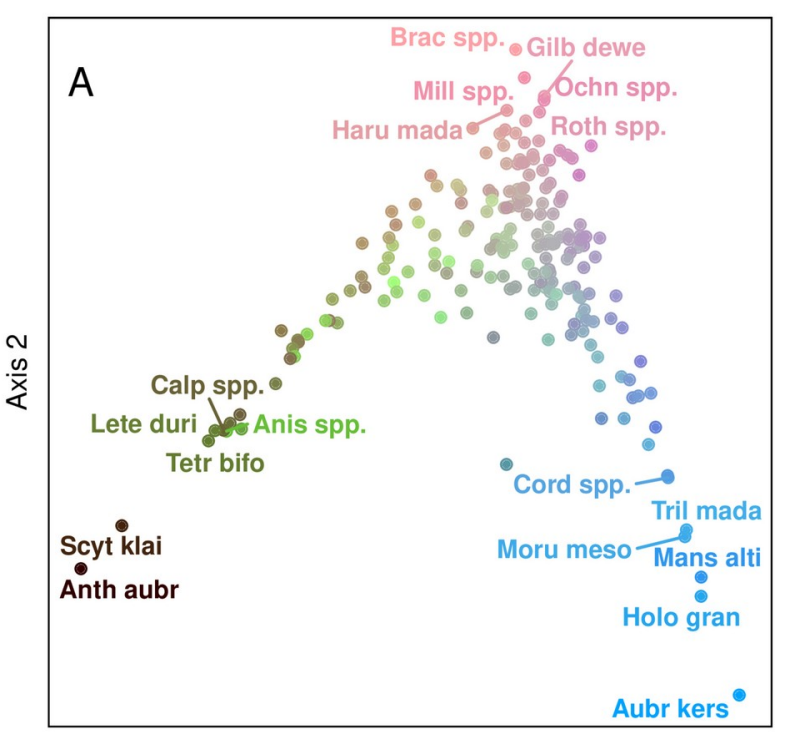

Axis 1

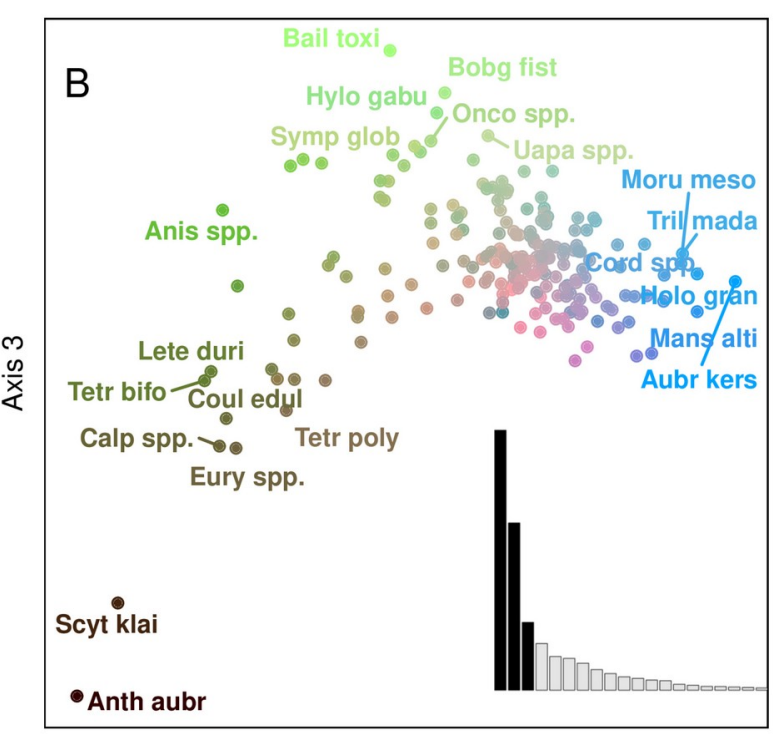

Axis 1

940

941 Extended Data Figure 2 | Taxon CA planes 1-2 (A) and 1-3 (B) with labels for the

94212 most representative taxa on each axis. Color code corresponds to that reported

943 in Fig. 1. The first eigenvalues are reported in the B panel, highligthing in black the first

944 three axes. Taxon codes and scores of the 193 taxa are given in Table S2.

945
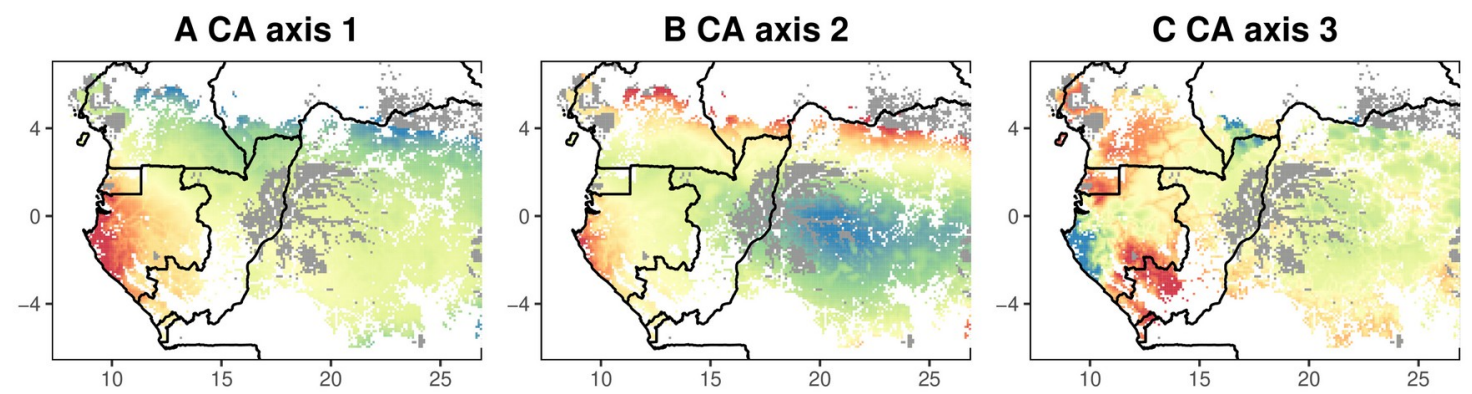

946 Extended Data Figure 3 | Individual predicted floristic gradients illustrated by the

947 three first axes of the correspondence analysis (CA) performed on predicted

948 taxon abundances. A composite map of these three axes is given in Fig. 1 and the

949 corresponding taxon CA planes are provided in Extended Data Fig. 2.

950 
A)

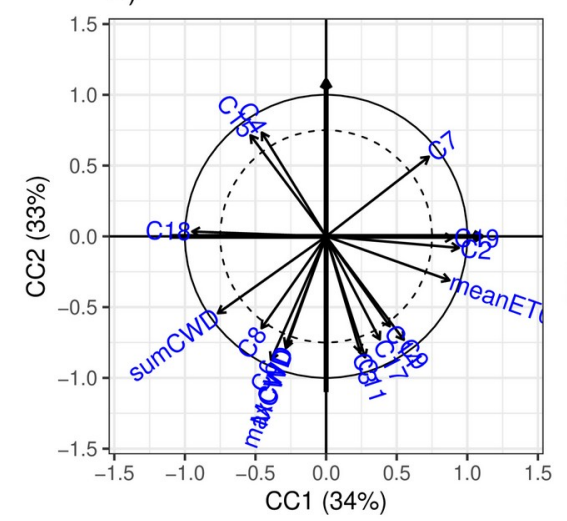

B)

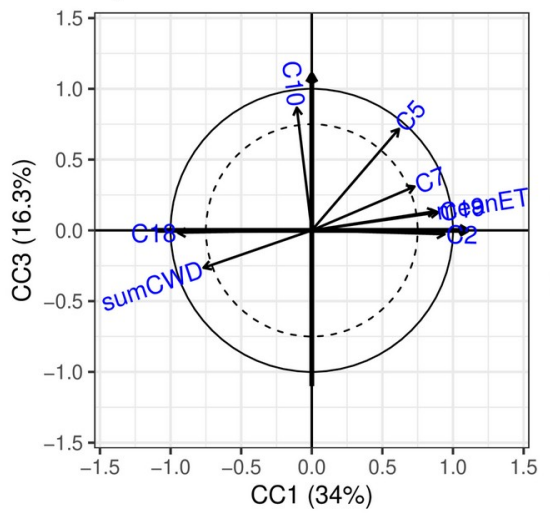

C)

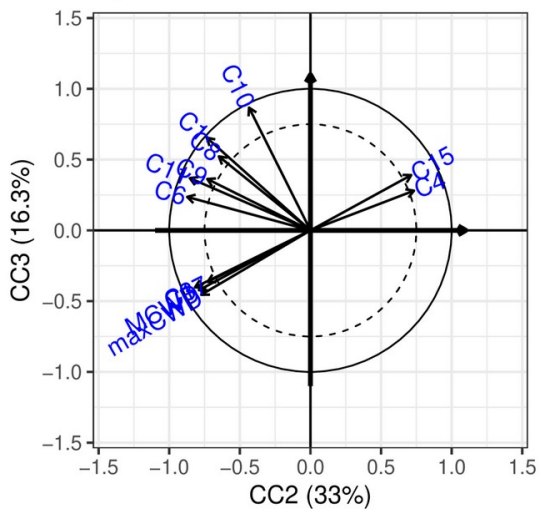

952 Extended Data Figure 4 | Plans 1-2 (A), 1-3 (B) and 2-3 (C) of the SCGLR climatic

953 components (CCs). All climatic variables having a correlation $<0.75$ with the two

954 components (dashed circle) were excluded for the sake of clarity. For abbreviations, see

955 Extended Data Table 2.

956

957

958

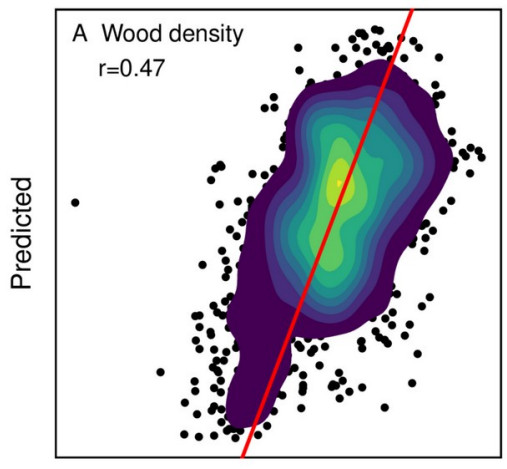

Observed

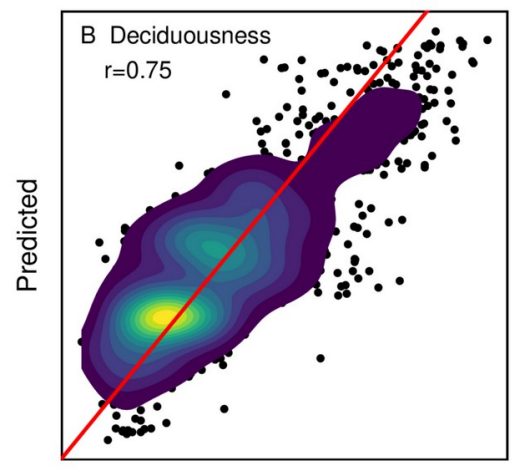

Observed

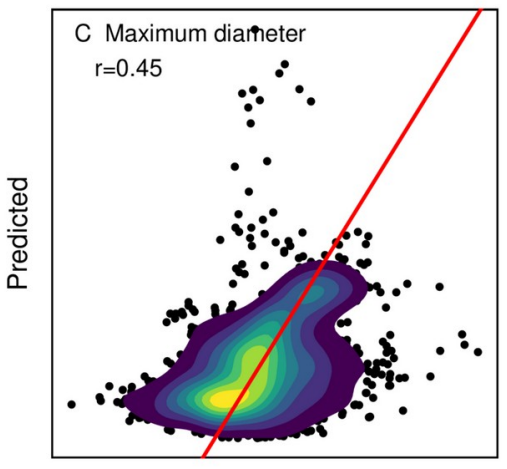

Observed

959 Extended Data Figure 5 | Spatial cross-validation results of the predictions of

960 functional assemblages. The observed and predicted community weighted mean trait

961 values within the $1,57110 \times 10-\mathrm{km}^{2}$ grid cells are given for $(\mathbf{A})$ wood density; (B)

962 deciduousness and $(\mathbf{C})$ maximum diameter. The 1:1 line is displayed in red. 

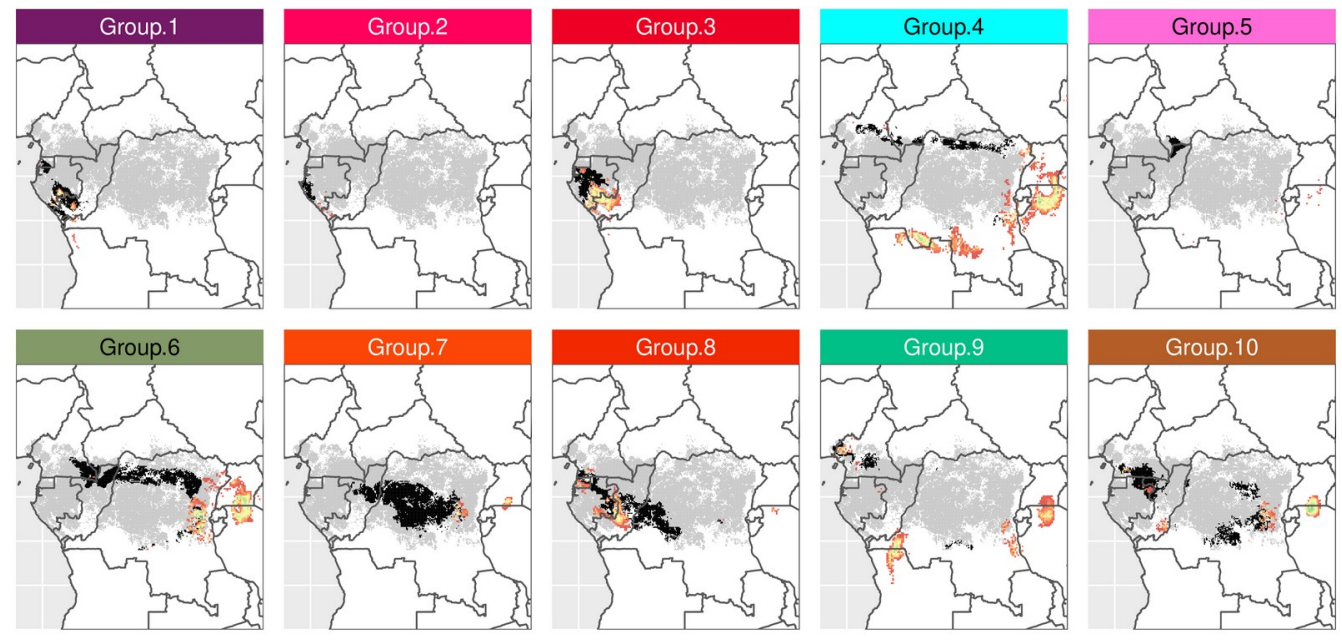

964

Current group distribution

Future favorable climatic conditions $5 \%$

965 Extended Data Figure 6 | Projected changes under RCP scenario 4.5 in 2085 of

966 the climatic conditions of the ten forest types. Areas where climate models predict

967 similar climatic components (CCs) values as those currently found within forest types (in

968 black) are illustrated with a color gradient indicating the level of agreement amongst the

96918 climate models (in \%; no color indicates that none of the original 18 climate models

970 predicted similar conditions). More specifically, we used 3D concave hull (alpha shape)

971 models to assess where the combinations of current Ccs corresponding to each forest

972 type are predicted to be represented in 2085.

973

974

975

976

977

978 
A Vulnerability to global change (RCP 4.5 2055)
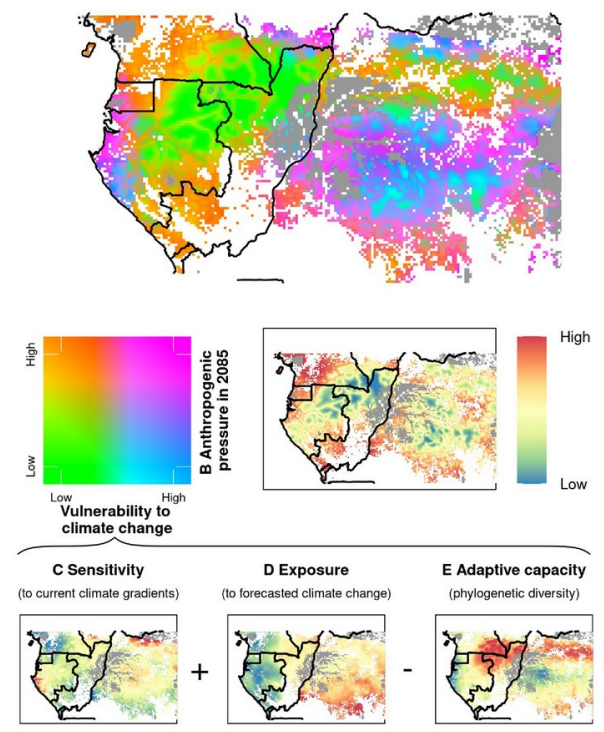

C Vulnerability to global change (RCP 4.5 2085)
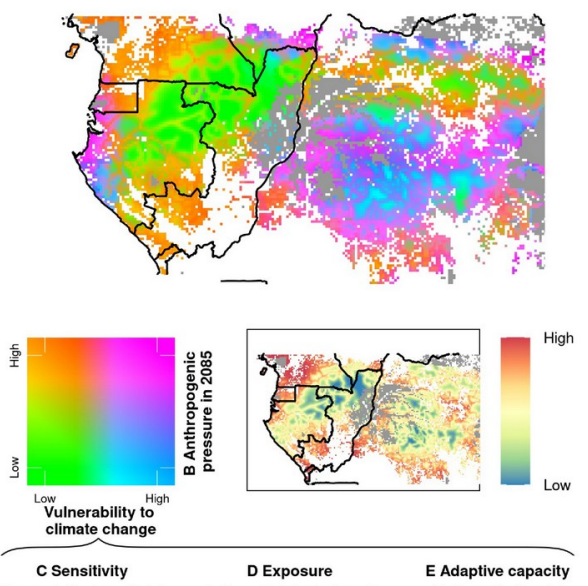
(to current climate gradients) (to forecasted climate change) $\begin{gathered}\text { E Adaptive capacity } \\ \text { (phylogenetic diversity) }\end{gathered}$

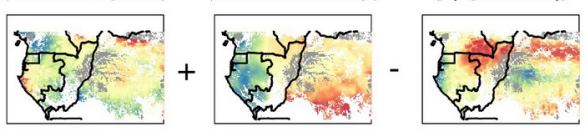

B Vulnerability to global change (RCP 8.5 2055)
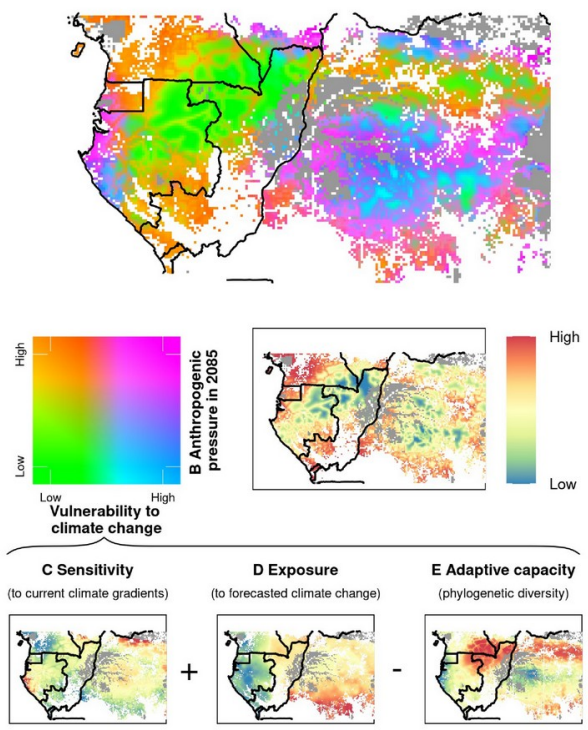

D Vulnerability to global change (RCP 8.5 2085)
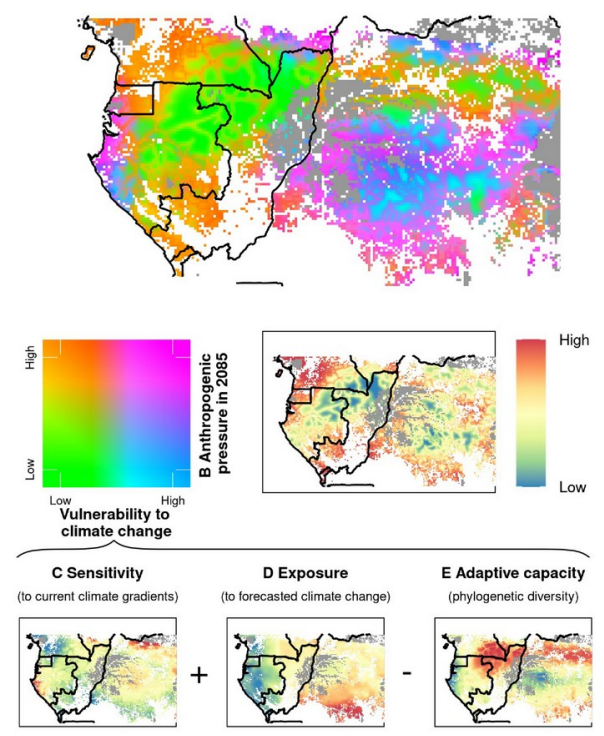

980 Extended Data Figure 7 | The vulnerability map under two different RCP

981 scenarios, RCP 4.5 and RCP 8.5, and for two years, year 2055 and year 2085. As

982 can be seen, the predicted vulnerability is little impacted by the IPCC scenario chosen

983 because it expresses a relative vulnerability over the study area and, if different

984 scenarios predict different amplitudes of climate change, spatial patterns of climate

985 exposure remains similar (see Methods). 


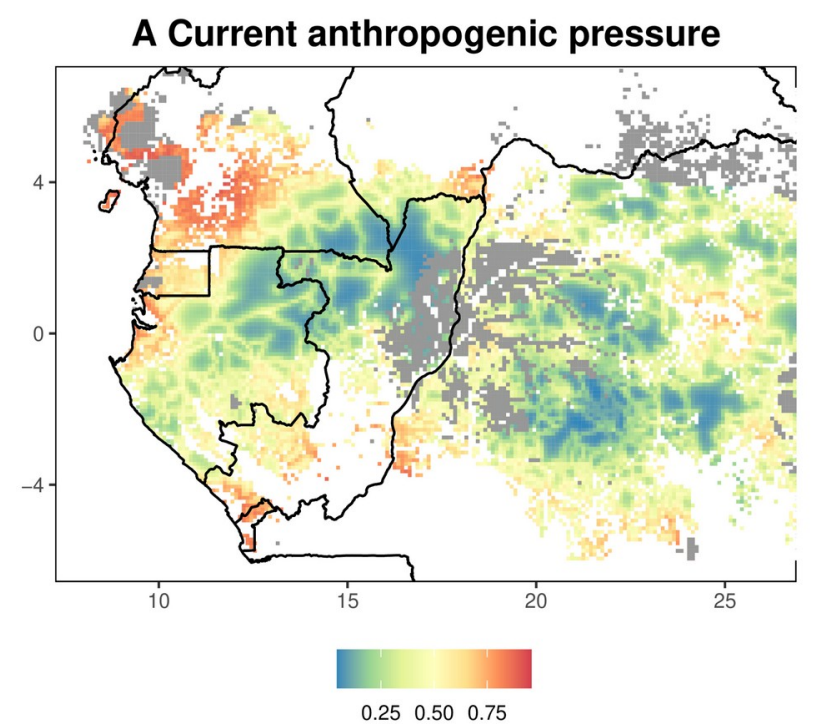

B Anthropogenic pressure projected in 2085

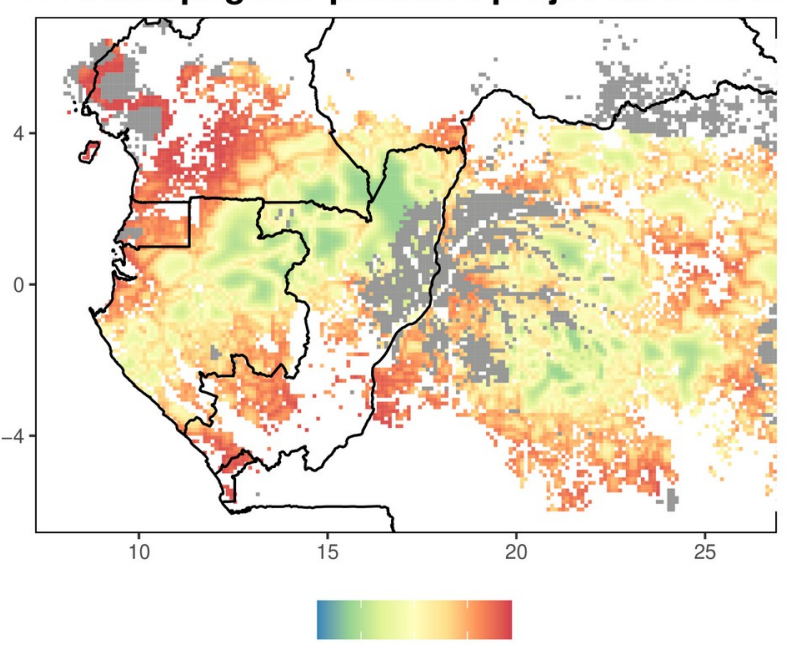

$0.250 .50 \quad 0.75$

987

988 Extended Data Figure 8 | Current and projected anthropogenic pressure over 989 central Africa predicted from our index of human-induced forest disturbance 990 intensity.

991 


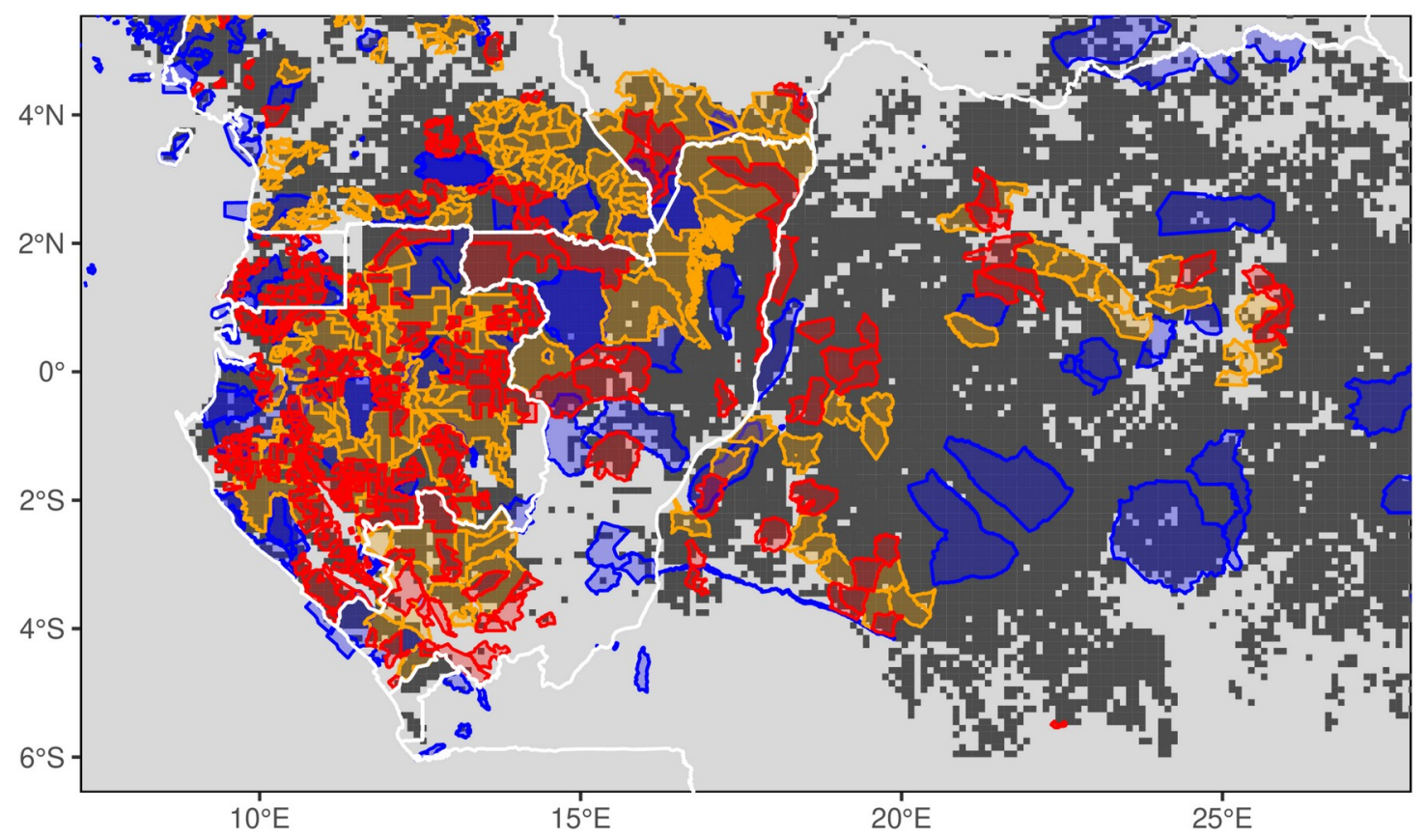

993

994 Extended Data Figure 9 | Protected area network (blue) and areas dedicated to

995 logging activities (orange and red) in central Africa. Data on protected areas were

996 obtained from the World Database on Protected Areas (last access: 14/08/2018)

997 excluding marine, hunting and game-oriented areas except for the Democratic Republic

998 of Congo where data from the World Resource Institute were used and downloaded

999 from ArcGIS hub (last access: 01/06/2019). Logging activity data were kindly provided

1000 by the Observatoire des Forêts d'Afrique Centrale based on an unpublished work

1001 completed in June 2018, except for DRC where more updated data (June 2019) were

1002 provided by the AGEDUFOR national project. Areas in orange illustrate forest

1003 concessions that are known to have, or to be in the process of having, an officially

1004 validated sustainable forest management plan. Red areas illustrate forest areas that are

1005 currently dedicated to logging but that either do not have an official management plan or

1006 have an uncertain status. 